\title{
Allicin Attenuated Advanced Oxidation Protein Product-Induced Oxidative Stress and Mitochondrial Apoptosis in Human Nucleus Pulposus Cells
}

\author{
Qian Xiang, Zhangrong Cheng, Juntan Wang, Xiaobo Feng, Wenbin Hua, Rongjin Luo, \\ Bingjin Wang, Zhiwei Liao, Liang Ma, Gaocai Li, Saideng Lu, Kun Wang, Yu Song, Shuai Li, \\ Xinghuo Wu, Cao Yang, and Yukun Zhang $\mathbb{D}$
}

Department of Orthopaedics, Union Hospital, Tongji Medical College, Huazhong University of Science and Technology, Wuhan 430022, China

Correspondence should be addressed to Yukun Zhang; zhangyukuncom@126.com

Received 4 October 2020; Revised 30 November 2020; Accepted 2 December 2020; Published 16 December 2020

Academic Editor: Sidong Yang

Copyright (C) 2020 Qian Xiang et al. This is an open access article distributed under the Creative Commons Attribution License, which permits unrestricted use, distribution, and reproduction in any medium, provided the original work is properly cited.

Intervertebral disc degeneration (IDD) is one of the most common chronic degenerative musculoskeletal disorders. Oxidative stress-induced apoptosis of the nucleus pulposus (NP) cells plays a key role during IDD progression. Advanced oxidation protein products (AOPP), novel biomarkers of oxidative stress, have been reported to function in various diseases due to their potential for disrupting the redox balance. The current study is aimed at investigating the function of AOPP in the oxidative stress-induced apoptosis of human NP cells and the alleviative effects of allicin during this process which was known for its antioxidant properties. AOPP were demonstrated to hamper the viability and proliferation of NP cells in a time- and concentration-dependent manner and cause cell apoptosis markedly. High levels of reactive oxygen species (ROS) and lipid peroxidation product malondialdehyde (MDA) were detected in NP cells after AOPP stimulation, which resulted in depolarized mitochondrial transmembrane potential (MTP). Correspondingly, higher levels of AOPP were discovered in the human degenerative intervertebral discs (IVD). It was also found that allicin could protect NP cells against AOPP-mediated oxidative stress and mitochondrial dysfunction via suppressing the p38-MAPK pathway. These results disclosed a significant role of AOPP in the oxidative stress-induced apoptosis of NP cells, which could be involved in the primary pathogenesis of IDD. It was also revealed that allicin could be a promising therapeutic approach against AOPP-mediated oxidative stress during IDD progression.

\section{Introduction}

Low back pain (LBP) has become an increasingly common disorder in contemporary times, lowering patients' quality of life and burthening cosmopolitan healthcare system and society economically $[1,2]$. One of the leading causes of LBP is intervertebral disc degeneration (IDD) [3]. The intervertebral disc, the largest avascular organ in the human body, comprises a centric nucleus pulposus (NP) and an ambient annulus fibrosus [4]. Many previous studies demonstrate that the main pathological changes in degenerated discs include excess apoptosis of NP cells and degradation of the extracellular matrix (ECM) $[5,6]$. Apoptosis is a highly conserved cellular function to remove excrescent and volatile cells in different pathophysiological processes, and plays a vital role in sustaining healthy function of tissues and organs; however, superfluous apoptosis of NP cells is the primary cause of IDD [7-9]. Recent studies have shown that excess apoptosis of NP cells is largely promoted by an imbalance of the cellular redox system in the disc microenvironment, while interventions targeting oxidative stress markedly protect NP cells from apoptosis $[10,11]$.

Once cellular redox homeostasis is disrupted, proteins in this environment are prone to be damaged under oxidative stress [12-14]. Advanced oxidation protein products (AOPP), which are important derivatives of such damaged 
proteins, mainly originate from oxidatively modified albumin and have been identified recently as circulating plasma biomarkers of oxidation stress [15]. Indeed, AOPP accumulate in the serum of patients with various chronic diseases, such as inflammatory bowel disease, diabetes, and chronic kidney disease [16]. A previous study revealed that reactive oxygen species (ROS), which are potent oxidants, can be generated by AOPP through a NADPH oxidase-dependent pathway [17]. Research on diabetic nephropathy also showed that the accumulation of AOPP can induce oxidative stress and mitochondrial injury [18]. Other studies demonstrated that AOPP can act as potent inducers of apoptosis $[19,20]$. Recently, abnormal accumulation of AOPP was found in the articular cartilage of rodent osteoarthritis (OA) models and had an endogenous pathogenic role in OA progression [21]. In addition, a prior study showed that AOPP participated in age-related changes in rat lumbar IVDs [22]. Considering that IVD cells and chondrocytes share phenotypic and morphological similarities, it is important to investigate how AOPP work in IDD progression, which remains unclear thus far [23].

Many constituents of medicinal herbs, including allicin, have various benefits [24]. Allicin, one of the organosulfur compounds extracted from the garlic bulb, shows potent effects on eliminating free radicals, abating oxidative stress, and protecting mitochondrial functions [25-28]. Recent studies have also demonstrated that allicin exerts extensive therapeutic effects in various diseases, such as cardiovascular and chronic kidney disease, because of its antioxidant properties, while its influence on IDD is still unknown [28-30].

Based on the above findings, we hypothesized that the accumulation of AOPP in the disc microenvironment might contribute to oxidative stress in NP cells, which further erode mitochondrial functions and promote apoptosis. The present study was undertaken to explore the role of AOPP in oxidative stress and apoptosis of human NP cells and to determine the effect of allicin on these AOPP-mediated processes. We exposed NP cells in vitro to different levels of AOPP or allicin and gathered experimental data on multiple aspects, such as cell proliferation, apoptosis, oxidative stress, and changes in the mitochondrial membrane. In addition, as an important avenue for cell demise, the activation of MAPK pathways was reported to be crucially involved in ROS-triggered apoptosis [31, 32]. Considering the role of ROS as a pathogenic intermediary of AOPP-initiated diseases, thus, we detected the expression of key proteins in MAPK signaling pathways potentially mediating the effects of AOPP on NP cells [17]. We aimed to provide a general overview of the molecular mechanisms by which AOPP affected human NP cells and inform possible therapeutic strategies. Our research is aimed at helping to better understand the pathogenesis of IDD and providing a promising therapeutic approach to retard its progression.

\section{Material and Methods}

2.1. Collection of NP Tissue and Ethics Statement. To separate NP cells, the healthy NP specimens (Pfirrmann I or II) of human IVD were obtained from deformity correction sur- gery for 6 patients ( 3 females and 3 males; average age: 18.3 years; age range: $16-20$ years) with idiopathic scoliosis. To compare AOPP levels, the degenerative NP tissues (Pfirrmann IV or V) were acquired from spinal decompression surgery for 3 patients ( 2 females and 1 male; average age 63.4 years; age range: $63-65$ years) with spinal stenosis, and the healthy tissues were collected from deformity correction surgery for 3 patients ( 2 males and 1 female; average age 25 years; age range: $24-26$ years) with idiopathic scoliosis. In brief, after being excised intraoperatively, the healthy tissues used for separating cells were instantly put into a chilled vessel with Hank's balanced salt solution, and the other healthy or degenerative tissues used for AOPP testing were snapfrozen. All samples were then transported to the laboratory for the further handling according to their intended use or cryopreserved in liquid nitrogen. Each donor was informed of the experimental usage of the NP tissue, and their approvals were acquired. Our research protocol was approved by the Clinical Research Ethics Committee of Tongji Medical College, Huazhong University of Science and Technology. All methods were applied in strict adherence with the approved guidelines.

2.2. Separation and Culture of NP Cells. Briefly, the fresh tissue was chopped into small pieces $\left(1 \mathrm{~mm}^{3}\right.$ or so) and digested at $37^{\circ} \mathrm{C}$ using $0.25 \%$ trypsin (Gibco, UK) for $30 \mathrm{~min}$ before $0.2 \%$ collagenase-type 2 (Gibco, UK) for $4 \mathrm{~h}$ in a humid environment with $5 \% \mathrm{CO}_{2}$. The suspension was centrifuged after the pieces were filtered and washed using phosphate buffered saline (PBS). Next, the cultivation of separate cells was conducted in Dulbecco's modified Eagle' medium (DMEM) comprising nutrient admixture F12 (Gibco, USA) and 15\% fetal bovine serum (FBS; Gibco, USA) and streptomycin $(100 \mu \mathrm{g} / \mathrm{ml}$; Gibco, USA) as well as penicillin (100 units/ml; Gibco, USA). The culture medium was renewed every three days until cell passaging was performed at $80 \%$ confluence. Fluorescently labeled antibodies against NP cell markers (CD24, ab31622; KRT18, ab215839; Abcam, UK) were used to identify the phenotype of NP cells, as described previously [33]. Cells at the second passage were utilized in the subsequent experiments.

2.3. AOPP Preparation and Assessment. Human serum albumin (HSA) solution $(30 \mathrm{mg} / \mathrm{ml})$ was incubated with $100 \mathrm{mM}$ $\mathrm{HOCl}$ in $\mathrm{PBS}(\mathrm{pH}=7.4)$ at ordinary temperature for $30 \mathrm{~min}$. An equimolar concentration of thiosulfate was used to discontinue the reaction and block excess $\mathrm{HOCl}$ before the solution was dialyzed for $24 \mathrm{~h}$ at $4^{\circ} \mathrm{C}$. AOPP-HSA were assessed according to previous description [34]. In short, the samples and $160 \mu \mathrm{L}$ citric acid $(0.20 \mathrm{~mol} / \mathrm{L})$ were added into a 96 -well microplate. Then, the calibrated chloramine-T model compound, $10 \mathrm{ml}$ potassium iodide (KI, $1.16 \mathrm{~mol} / \mathrm{L}$ in $\mathrm{PBS}$ ), and $10 \mu \mathrm{L}$ citric acid $(0.20 \mathrm{~mol} / \mathrm{L})$ were successively pipetted into the plate. Next, the absorbance was read on a spectrophotometer (Waltham, MA, USA) at $340 \mathrm{~nm}$. The level of AOPP was expressed as $\mu \mathrm{Mol} / \mathrm{ml}$ of chloramine-T equivalents.

2.4. Protocols of NP Cell Culture and Treatment. To evaluate the impact of AOPP, the NP cells were either cotreated with 
incremental concentrations of $\operatorname{AOPP}(0,100,200$, and $400 \mu \mathrm{g} / \mathrm{ml}$ ) for $24 \mathrm{~h}$, or with $400 \mu \mathrm{g} / \mathrm{ml}$ AOPP for different time points $(0,2,6,12$, and $24 \mathrm{~h})$. Allicin (purity $>98 \%$ ) was bought from MedChemExpress (Shanghai, China). The cells were cotreated with incremental levels of allicin $(0,5$, 10,20 , and $40 \mu \mathrm{M}$ ) for $24 \mathrm{~h}$ to explore the effect of allicin on them. Then, to evaluate the possible protective role of allicin against AOPP-induced unfavorable influences including restrained viability and proliferation, apoptosis, oxidative stress, and mitochondrial dysfunction, the cells were pretreated with incremental concentrations $(0,5,10$, and $20 \mu \mathrm{M})$ of allicin for $2 \mathrm{~h}$ and then with AOPP $(400 \mu \mathrm{g} / \mathrm{ml})$ for $24 \mathrm{~h}$. To examine whether MAPK pathways were activated in AOPP-induced oxidative damage, NP cells were treated with $400 \mu \mathrm{g} / \mathrm{ml}$ AOPP. To explore the signaling pathway through which allicin mitigated AOPP-induced oxidative stress and apoptosis of NP cells, the cells in the experimental groups were pretreated with different concentrations of allicin $(0,5,10$, and $20 \mu \mathrm{M})$ for $2 \mathrm{~h}$, and then cotreated with AOPP $(400 \mu \mathrm{g} / \mathrm{ml})$ for $24 \mathrm{~h}$. To validate the MAPK pathway underlying the protective effects of allicin against AOPP, the NP cells were treated, respectively, with allicin $(10 \mu \mathrm{M})$, p38-MAPK inhibitor SB202190 $(10 \mu \mathrm{M})$, JNK inhibitor SP600125 $(10 \mu \mathrm{M})$, and ERK inhibitor SCH772984 $(10 \mu \mathrm{M})$ for $2 \mathrm{~h}$, and then with AOPP $(400 \mu \mathrm{g} / \mathrm{ml})$ for $24 \mathrm{~h}$. To examine whether the p38-MAPK agonist can block the positive effects of allicin, the human NP cells were pretreated with allicin $(10 \mu \mathrm{M})$ or allicin $(10 \mu \mathrm{M})$ in combination with p38-MAPK activator Dehydrocorydaline chloride (Dc, $500 \mathrm{nM}$ ) for $2 \mathrm{~h}$, then treated with AOPP $(400 \mu \mathrm{g} / \mathrm{ml})$ for $24 \mathrm{~h}$.

2.5. Appraisals of NP Cell Viability and Proliferation. The viability of human NP cells treated with allicin or AOPP was evaluated employing CCK-8 assay (Dojindo, Japan). Briefly, suspended human NP cells were pipetted into a 96-well plate for $24 \mathrm{~h}$ incubation, and then the cells were cotreated with incremental concentrations of allicin or AOPP for different time periods. Afterward, NP cells in each well were appended with $10 \mu \mathrm{L}$ solution of CCK- 8 and then were cultured in the fresh medium at $37^{\circ} \mathrm{C}$ for $4 \mathrm{~h}$. Eventually, the absorbance at $450 \mathrm{~nm}$ was gauged employing a spectrophotometer (BioTek, Winooski, USA).

The evaluation of NP cell proliferation was performed with a BeyoClickEdU-488 Cell Proliferation kit (Beyotime, Shanghai, China). The procedures were mainly in accord with instructions of the manufacturer. The images were acquired employing fluorescent microscopy (Olympus IX71, Japan).

2.6. Flow Cytometry for Analyzing Apoptosis, ROS, and MTP. Human NP cells were harvested after being treated in each group. An Annexin V-FITC Apoptosis Detection Kit (KeyGEN, China) was utilized to estimate the apoptotic levels of NP cells. The alterations of MTP were measured utilizing the cationic fluorescent indicator JC-1 (Beyotime). The ROS levels of cells were detected using the fluorescent dye dihydroethidium (DHE, Beyotime). The fluorescence intensity emitted by DHE was measured by flow cytometry, and
ROS levels were expressed as mean fluorescence intensity for comparison. The final ROS level of each experimental group was expressed as a ratio relative to that of control group. All the above procedures were in accordance with previous descriptions [35]. Analysis of the sample was by dint of a FACSCalibur flow cytometer (BD Biosciences).

2.7. Lipid Peroxidation Detection. A malondialdehyde (MDA) Assay Kit (Beyotime, China) was used to detect the cellular lipid peroxidation. MDA is considered as a distinctive peroxidative product of lipid. Briefly speaking, NP cells were dissolved in MDA standards before blending with the working solution of thiobarbituric acid (TBA), in accordance with instructions. The absorbance of the MDA-TBA compound was gauged at $532 \mathrm{~nm}$ by using an automatic microplate reader (Multiskan MK3, Thermo Scientific, USA). The level of cellular MDA was reckoned on the basis of the standard curve.

2.8. Immunofluorescence Staining. Immunofluorescence staining was done to NP cells according to previous descriptions [36]. Primary antibodies aiming at cleaved caspase-3 (1: 400; \#9579, Cell Signaling Technology) were first used to incubate with NP cells at $4^{\circ} \mathrm{C}$ for all night. In the second day, a continued incubation with the secondary antibodies Cy3 conjugated goat anti-rabbit IgG (1:200; BA1032, Boster Biological Technology) lasted for $2 \mathrm{~h}$. DAPI (Beyotime) was used to stain the nuclei. Images of fluorescence were obtained via immunofluorescent microscopy (Olympus IX71, Japan) as well as confocal laser-scanning microscopy (LSM780, ZEISS, Germany). The immunofluorescence intensity values were determined using the ImageJ image analysis software (NIH). For the stained sample from each group, the mean immunofluorescence was determined by analyzing the fluorescence intensity values of three randomly selected images under the same magnification $(\times 400)$. In order to compare the fluorescence intensity between groups, all the image analyses were performed using the same protocol. The final fluorescence intensity of each experiment group was expressed as a ratio relative to that of control group.

2.9. Western Blotting. The total and cytoplasmic, as well as mitochondrial proteins from elaborately treated NP cells were extracted employing the commercial kits, following the merchant guide (Beyotime, China). Levels of these proteins were then gauged employing an Enhanced BCA Protein Assay Kit (Beyotime, China). 10-12\% SDS-PAGE gels were used to separate these proteins, which were then transferred to polyvinylidene fluoride (PVDF) membranes (Millipore, USA). The PVDF membranes were previously blocked before an overnight incubation at $4^{\circ} \mathrm{C}$ with primary antibodies $(1: 500-1: 1000)$ and then with horseradish peroxidase(HRP-) conjugated secondary antibodies (1:2000; Abcam). Enhanced chemiluminescence reagents (Amersham, Piscataway, USA) were utilized to examine the expressed proteins. Primary antibodies against the following molecules were used: Bax (ab32503, Abcam), cytochrome-c (ab133504, Abcam), cleaved caspase-3 (\#9579, Cell signaling Technology), Bcl-2 (ab196495, Abcam), VDAC1 (sc-32063, Santa 
Cruz Bio-technology), cleaved caspase-9 (\#9505, Cell Signaling Technology), GAPDH (\#5174, Cell Signaling Technology), MAPK Family Antibody Sampler Kit (\#8690, \#4695, and \#9252; Cell Signaling Technology), and PhosphoMAPK Family Antibody Sampler Kit (\#4511, \#4370, and \#4668; Cell Signaling Technology).

2.10. Enzyme-Linked Immunosorbent Assay (ELISA) for $A O P P$ Testing. After being weighted, the NP tissues were cut into pieces, mixed with PBS solution ( $9 \mathrm{ml}$ per gram), and fully ground. Then, the sample was centrifuged (C2500-R-230V, Labnet, USA) at $1000 \times \mathrm{g}$ for $20 \mathrm{~min}$. The supernatant was collected and tested with ELISA Kit for AOPP (Cloud-Clone Corp, USA) according to the manual. The optical density (O.D. value) of each well was measured at $450 \mathrm{~nm}$ using a microplate reader (Multiskan MK3, Thermo scientific). The concentrations of AOPP were calculated from the standard curve according to the manufacturer's instructions.

2.11. Data Analysis. All experiments were independently replicated at least three times. The analysis of data was finished with the SPSS v.18.0 software (USA). The data from all groups were presented as means $\pm \mathrm{SD}$ (standard deviation). Contrastive analysis of means between groups was evaluated using Student's $t$-test or one-way analysis of variance (ANOVA) with post hoc analysis using the Tukey's test. Graphic analysis of the data was conducted using GraphPad Prism 7.0 (GraphPad Software, California, USA). $p<0.05$ was the prerequisite to conclude that differences among statistics were meaningful.

\section{Results}

3.1. AOPP Inhibited NP Cell Viability and Proliferation and Were Accumulated in the Degenerative IVD. To explore the impact of AOPP on the viability and proliferation of NP cells in vitro, a group of human NP cells were treated with incremental concentrations of $\operatorname{AOPP}(0,100,200$, and $400 \mu \mathrm{g} / \mathrm{ml})$ made from human serum albumin (HSA) for $24 \mathrm{~h}$, and then another contrastive group was treated with a high level of AOPP $(400 \mu \mathrm{g} / \mathrm{ml})$ for different times $(0,2,6,12$, and $24 \mathrm{~h})$. Compared with the control, the AOPP-treated groups showed suppressed cell viability and proliferation, detected by CCK- 8 kit and EdU staining, respectively. Notably, this visualized inhibition was both dose-dependent and timedependent as depicted (Figures 1(a)-1(d)). Moreover, to explore the clinical relevance of the current study, we compared the levels of AOPP between the control human IVD tissues (Pfirrmann I or II) and the degenerative IVD tissues (Pfirrmann IV or V). Results showed that the levels of AOPP in degenerative tissues were significantly higher than that of control tissues (Figure S1(c)).

3.2. Effect of Allicin on NP Cell Viability and Proliferation. To explore the cytotoxic effect of allicin on NP cells, incremental concentrations of allicin $(0,5,10,20$, and $40 \mu \mathrm{M})$ were separately appended to independent groups for $24 \mathrm{~h}$. The CCK-8 assay and EdU staining showed that incubation with $<40 \mu \mathrm{M}$ allicin enhanced the cell viability and proliferation, which reached the highest level when the allicin was around $10 \mu \mathrm{M}$. However, the concentration growing from a critical value between $20 \mu \mathrm{M}$ and $40 \mu \mathrm{M}$ showed inhibition to cell viability and proliferation as presented in the figure (Figures 2(a) and 2(b)).

3.3. Allicin Improved the Viability and Proliferation of AOPPStimulated NP Cells. Considering the critical value of the beneficial dosage, we used $0,5,10$, and $20 \mu \mathrm{M}$ allicin to pretreat the NP cells for $2 \mathrm{~h}$, which were then cotreated with AOPPHSA for $24 \mathrm{~h}$. Unsurprisingly, allicin pretreatment attenuated the impaired viability and proliferation of NP cells under AOPP challenge, which were measured employing CCK- 8 and EdU staining. In addition, the most beneficial concentration of allicin was around $10 \mu \mathrm{M}$ (Figures 2(c) and $2(\mathrm{~d})$ ).

3.4. Allicin Protected NP Cells from AOPP-Induced Apoptosis. Apoptosis of NP cells was detected employing the Annexin V-FITC Apoptosis Detection Kit (KeyGEN, China). After treated by $400 \mu \mathrm{g} / \mathrm{ml}$ AOPP for $24 \mathrm{~h}$, the NP cells exhibited a high apoptosis rate $(>30 \%)$ compared with that $(<10 \%)$ of the control group (Figure 3(a)). However, when pretreated with different levels of allicin $(5,10$, and $20 \mu \mathrm{M}), 10$ and $20 \mu \mathrm{M}$ allicin pretreatment groups showed reduced apoptosis rate compared with the AOPP alone treatment group. It was of note that $10 \mu \mathrm{M}$ seemed to be the best protective concentration of allicin against AOPP-induced apoptosis (Figure 3(a)). Also, apoptosis-associated proteins were measured by using Western blotting. As expected, common proapoptotic proteins including Bax, cleaved caspase-3, cytoplasmic cytochrome-c, and cleaved caspase- 9 were highly promoted in the AOPP-treated group, while that in allicin-pretreated groups were relatively abated, especially in the $10 \mu \mathrm{M}$ allicin group. Correspondingly, antiapoptotic Bcl-2 and mitochondrial cytochrome-c were lowered in the group only treated with high levels of AOPP, while that were raised in allicin-pretreated groups, particularly in the $10 \mu \mathrm{M}$ allicin group. To detect cleaved caspase-3, another assay, immunofluorescence staining, was also employed to appraise the apoptotic differences among groups. Results showed that cleaved caspase- 3 was highly expressed in AOPP group compared with allicin groups, where the level of cleaved caspase-3 dropped to varying degrees. In summary, these results indicated that allicin worked in resisting AOPP-induced apoptosis to protect NP cells.

3.5. Allicin Protected NP Cells from Oxidative Stress and Mitochondrial Dysfunction Induced by AOPP. Next, we explored the mechanisms behind AOPP-induced apoptosis and how allicin antagonized it. AOPP have been reported to cause mitochondrial dysfunction through a ROSdependent way, which might expound the apoptosis phenomenon of NP cells [37]. Here, the dihydroethidium(DHE-) dyed products of ROS were detected by flow cytometry. The results showed that AOPP evidently increased ROS levels in NP cells, while allicin pretreatment partially restrained this effect (Figures 4(a)-4(c)). Moreover, we detected the level of MDA, a characteristic peroxidative 


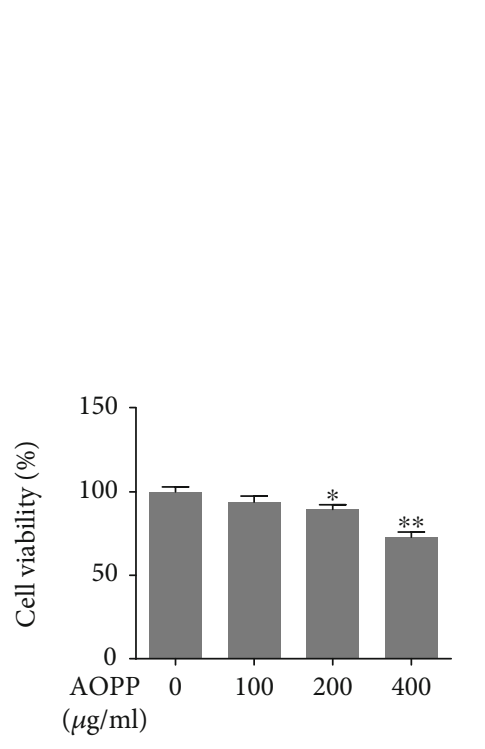

(a)
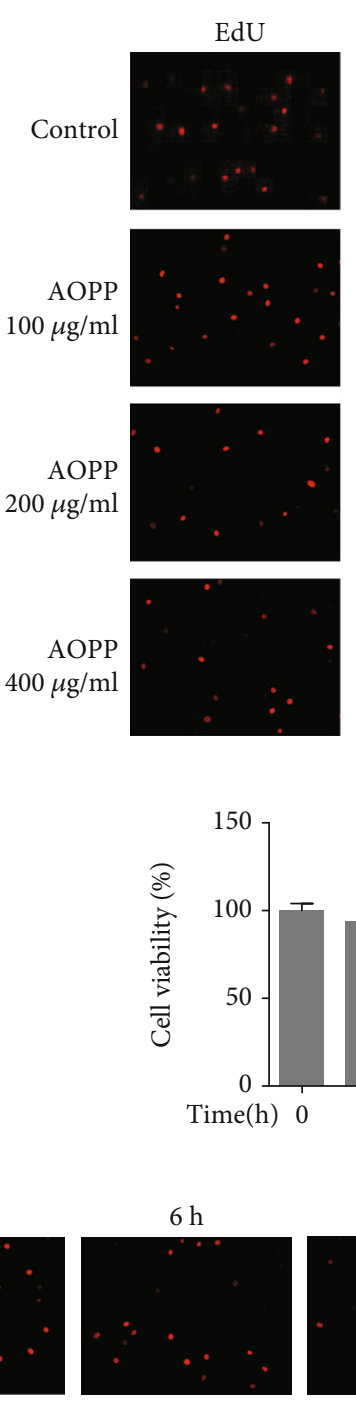
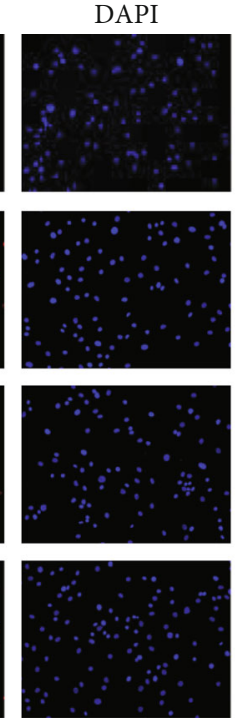

(b)
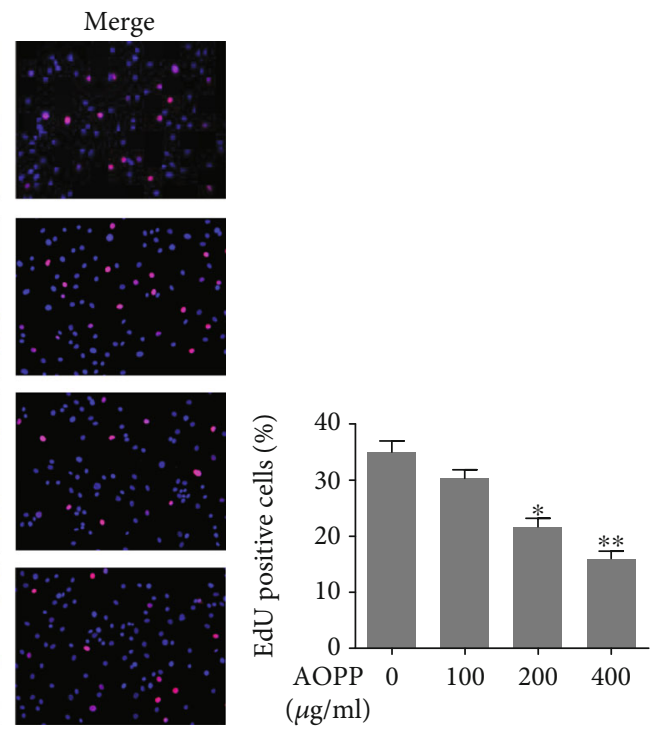
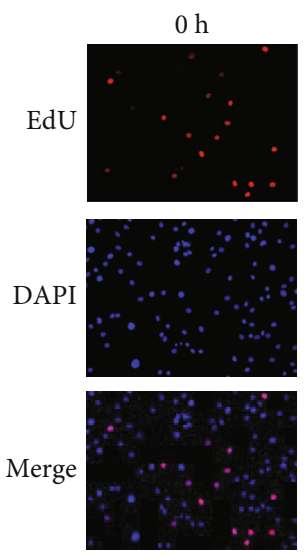

$2 \mathrm{~h}$
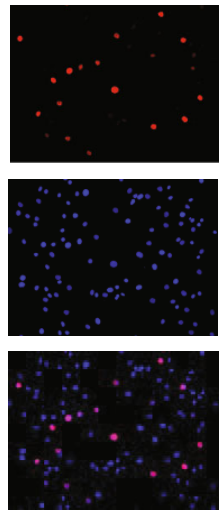
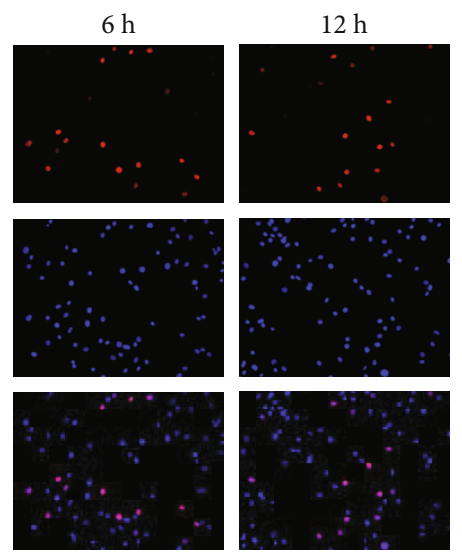
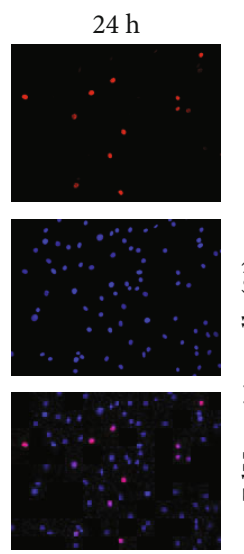

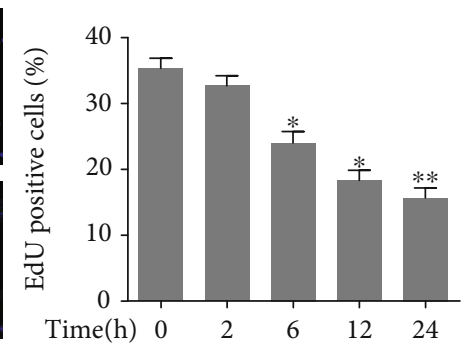

(d)

FIGURE 1: AOPP treatment inhibited human NP cell viability and proliferation in a dose- and time-dependent manner. (a) The human NP cells were treated with AOPP $(0,100,200$, and $400 \mu \mathrm{g} / \mathrm{ml})$ for $24 \mathrm{~h}$, and $0 \mu \mathrm{g} / \mathrm{ml}$ group served as a control. The cell viability of each group was detected by a CCK- 8 assay. (b) The human NP cells were treated with AOPP $(0-400 \mu \mathrm{g} / \mathrm{ml})$ for $24 \mathrm{~h}$, and $0 \mu \mathrm{g} / \mathrm{ml}$ group served as a control. The cell proliferation was determined using EdU staining combined with DAPI staining for the nuclei under fluorescence microscope, with the EdU positive cells quantitated. Original magnification: $\times 200$. (c) The human NP cells were treated with $400 \mu \mathrm{g} / \mathrm{ml} \mathrm{AOPP}$ for $0 \mathrm{~h}, 2 \mathrm{~h}, 6 \mathrm{~h}$, $12 \mathrm{~h}$, and $24 \mathrm{~h}$, and $0 \mathrm{~h}$ group served as a control. The cell viability of each group was detected by a CCK-8 assay. (d) The human NP cells were treated with $400 \mu \mathrm{g} / \mathrm{ml}$ AOPP for $0 \mathrm{~h}, 2 \mathrm{~h}, 6 \mathrm{~h}, 12 \mathrm{~h}$, and $24 \mathrm{~h}$, and $0 \mathrm{~h}$ group served as a control. The cell proliferation was determined using EdU staining combined with DAPI staining for the nuclei under fluorescence microscope, with the EdU positive cells quantitated. Original magnification: $\times 200$. Data were represented as mean \pm SD. ${ }^{*} p<0.05$ and ${ }^{* *} p<0.01$ versus the control group, $n=3$.

product of lipid. We found that the AOPP challenge promoted the MDA generation, which was inhibited partially by allicin pretreatment (Figure $4(\mathrm{~d})$ ). To appraise the func- tion of mitochondria under oxidative stress, we turned our attention to the MTP, whose depolarization proved the key event of intrinsic apoptosis. JC-1 assay indicated that the 


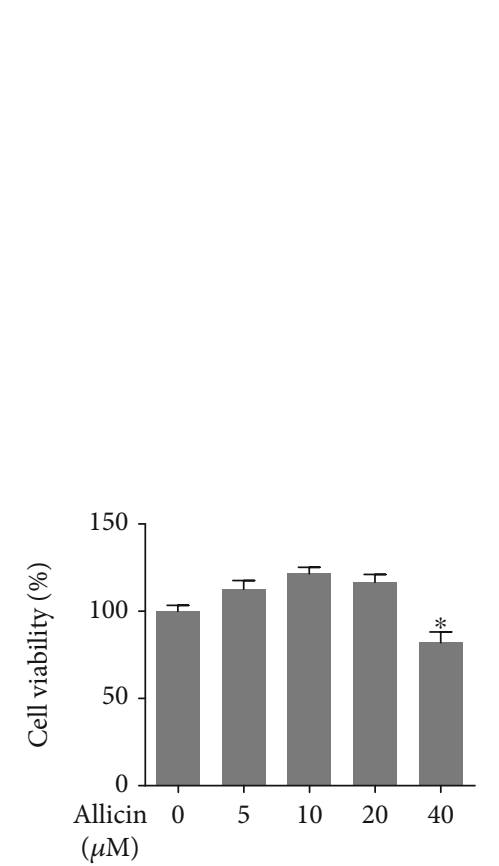

(a)
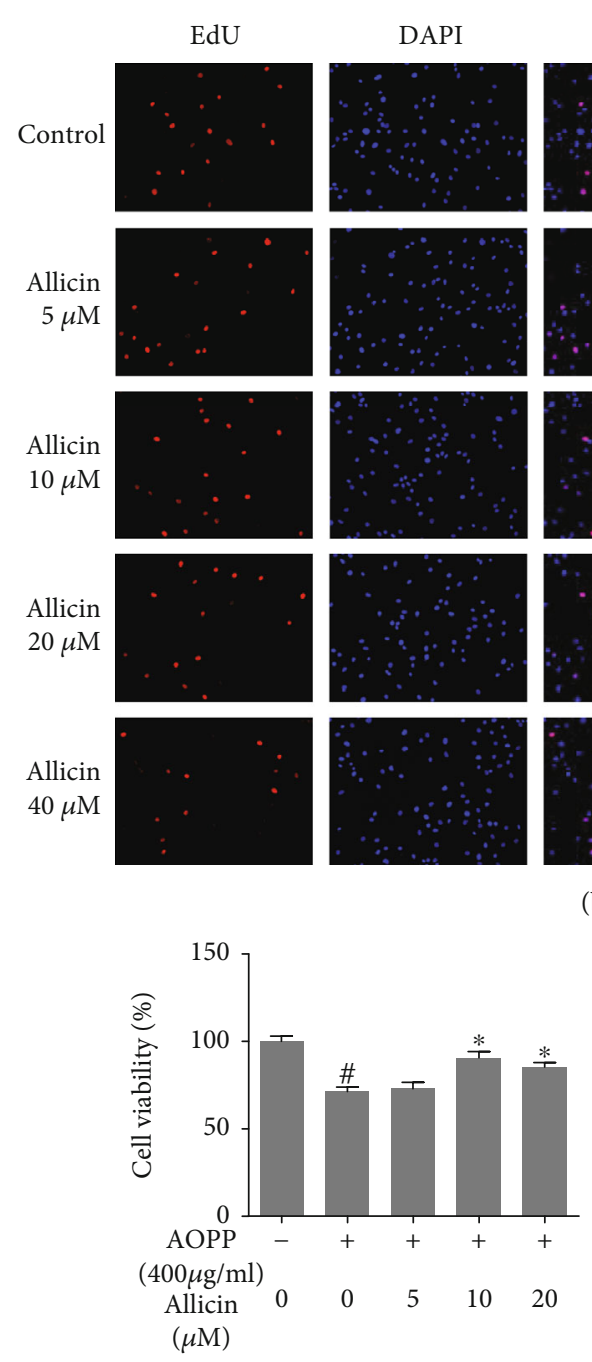

(c)
DAPI
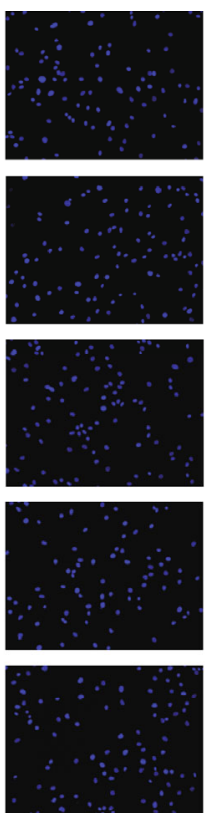
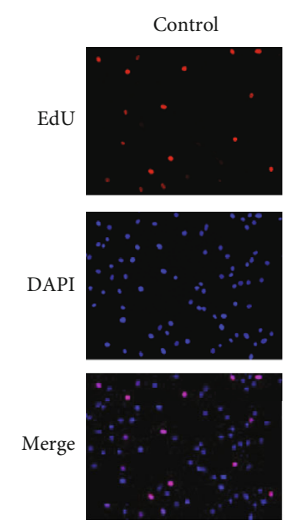
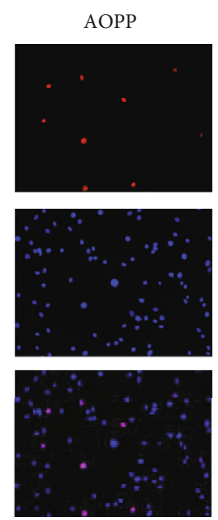
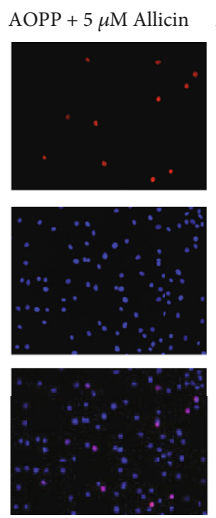
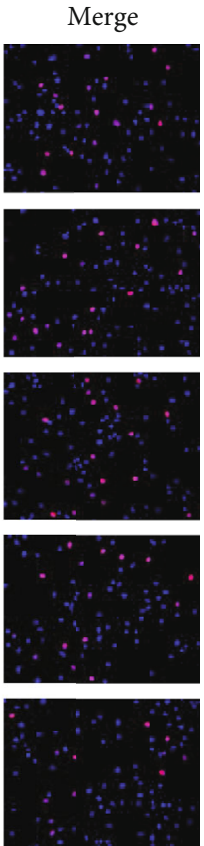

(b)

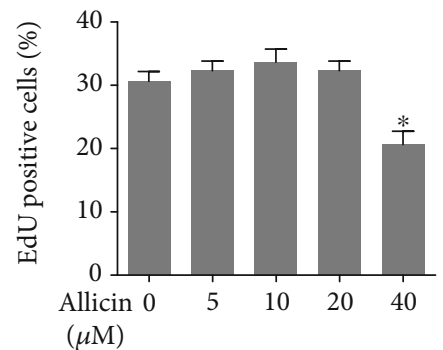

$(\mu \mathrm{M})$
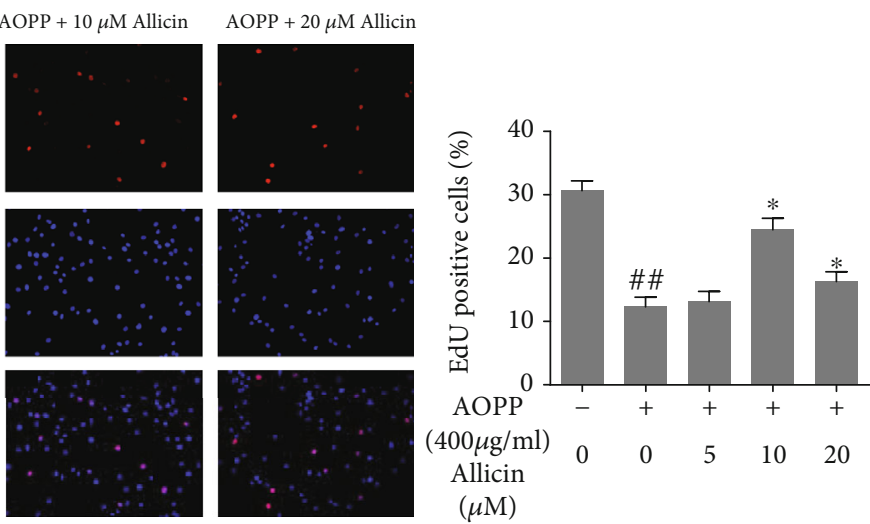

(d)

Figure 2: Effects of allicin on the human NP cell viability and proliferation. (a) The human NP cells were treated with allicin $(0,5,10,20$, and $40 \mu \mathrm{M}$ ) for $24 \mathrm{~h}$, and $0 \mu \mathrm{M}$ group served as a control. The cell viability of each group was detected by a CCK- 8 assay. ${ }^{*} p<0.05$ versus the control group, $n=3$. (b) The human NP cells were treated with allicin $(0-40 \mu \mathrm{M})$ for $24 \mathrm{~h}$, and $0 \mu \mathrm{M}$ group served as a control. The cell proliferation was determined using EdU staining combined with DAPI staining for the nuclei under fluorescence microscope, with the EdU positive cells quantitated. Original magnification: $\times 200$. ${ }^{*} p<0.05$ versus the control group, $n=3$. (c) The human NP cells pretreated by allicin $(0,5,10$, and $20 \mu \mathrm{M})$ were treated with $400 \mu \mathrm{g} / \mathrm{ml}$ AOPP, and the cell viability of each group was examined by the CCK- 8 assay. ${ }^{\#} p<0.05$ versus the control group, ${ }^{*} p<0.05$ versus the AOPP alone treatment group, $n=3$. (d) The cell proliferation of each group was determined using EdU staining under fluorescence microscope, with the EdU positive cells quantitated. Original magnification: $\times 200$. Data were represented as mean $\pm \mathrm{SD}$. ${ }^{\# \#} p<0.01$ versus the control group, ${ }^{*} p<0.05$ versus the AOPP alone treatment group, $n=3$. 


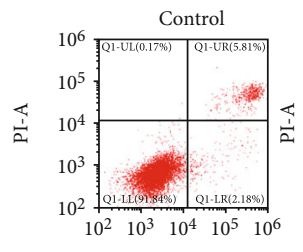

FITC-A

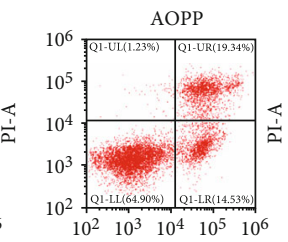

FITC-A

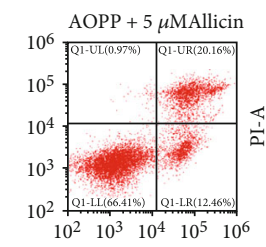

FITC-A

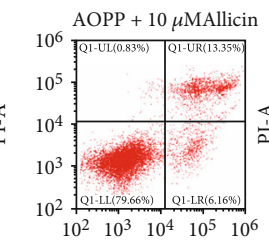

FITC-A

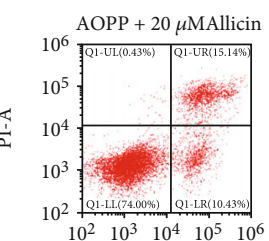

FITC-A

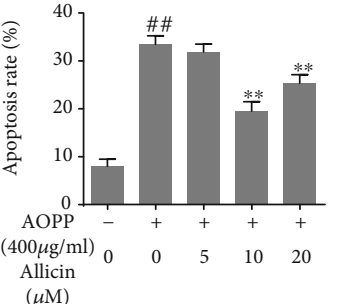

$(\mu \mathrm{M})$

(a)

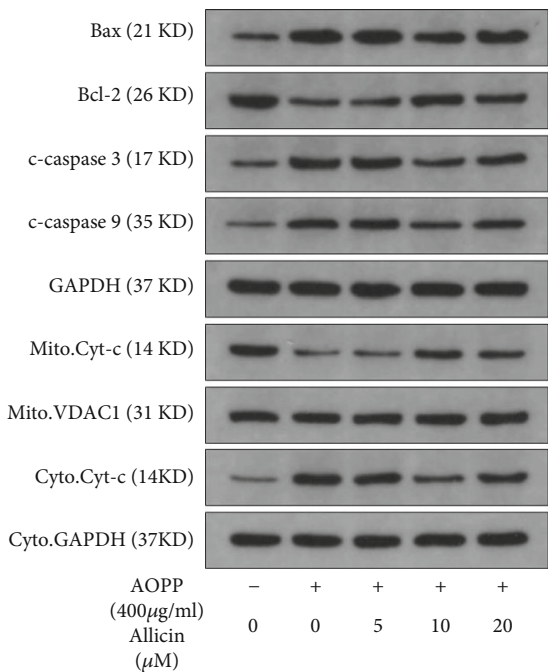

(b)

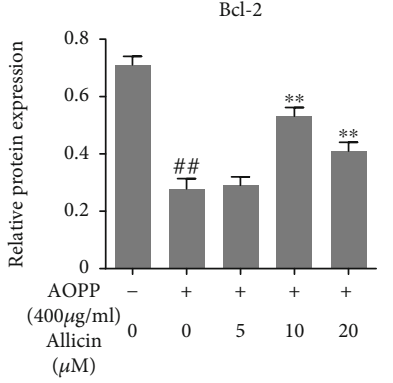

(d)

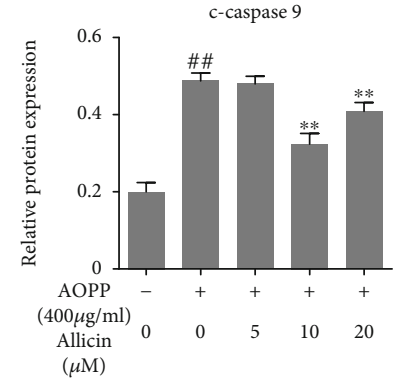

(f)

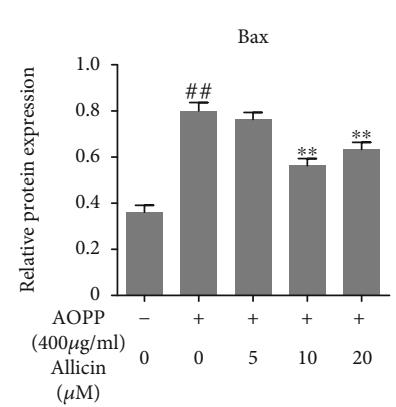

(c)

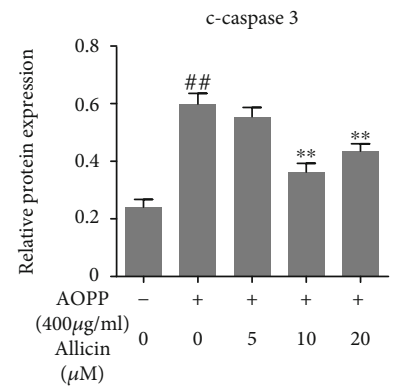

(e)

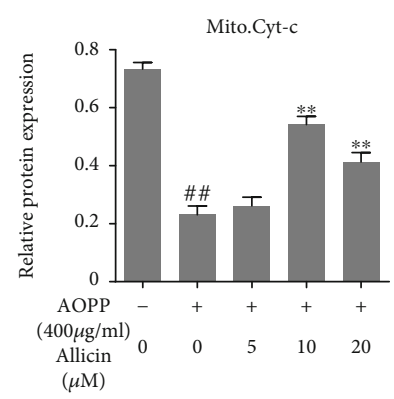

(g)

Figure 3: Continued. 


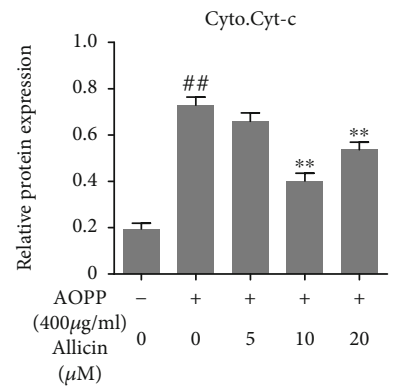

(h)
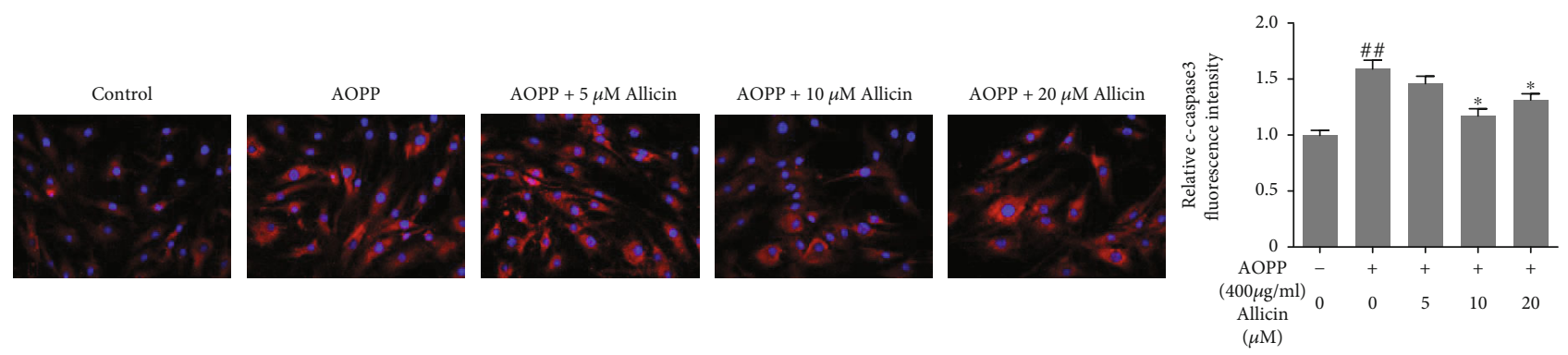

(i)

FIGURE 3: Allicin treatment alleviated AOPP-induced human NP cell apoptosis. (a) The human NP cells were pretreated with various concentrations of allicin $(0,5,10$, and $20 \mu \mathrm{M})$ for $2 \mathrm{~h}$, followed by stimulation with $400 \mu \mathrm{g} / \mathrm{ml}$ AOPP for $24 \mathrm{~h}$. And the rate of cell apoptosis was detected by flow cytometry with Annexin V-FITC/PI dual staining. The proportion of apoptotic cells in the first and fourth quadrant was measured for analysis. (b-h) The protein levels of Bax, Bcl-2, c-caspase 3, c-caspase 9, mitochondrial Cyt-c, and cytoplasmic Cyt-c were determined using Western blotting analysis (b) and quantified in (c-h). (i) Representative images of immunofluorescence staining for cleaved caspase- 3 in each group, with the relative fluorescence intensity quantified. Original magnification: $\times 400$. Data were represented as mean $\pm \mathrm{SD}$. ${ }^{\# \#} p<0.01$ versus the control group; ${ }^{*} p<0.05$ and ${ }^{* *} p<0.01$ versus the AOPP alone treatment group, $n=3$.

MTP was decreased markedly due to AOPP stimulation, while allicin pretreatment could attenuate this damage to some extent (Figure 4(e)). In summary, allicin pretreatment attenuated oxidative stress and mitochondrial dysfunction induced by AOPP in NP cells.

3.6. Allicin Protected against AOPP Mediated Oxidative Stress and Mitochondrial Apoptosis via Suppressing the p38-MAPK Pathway. Activation of MAPK pathways constitutes a key component in oxidative stress-associated apoptosis [38]. To ascertain the signaling pathway underlying apoptosis of NP cells stimulated by AOPP, Western blotting was performed to appraise the levels of MAPK subfamilies: p38, p-p38, ERK, p-ERK, JNK, and p-JNK. The results showed that AOPP treatment markedly increased the expression of all the above proteins associated with MAPK pathways (Figures 5(a)-5(d)). Therefore, MAPK signaling pathways might play an important role in AOPP-induced apoptosis of human NP cells. Next, we detected the levels of activated MAPK pathways in allicin-pretreated groups. Unsurprisingly, allicin pretreatment suppressed the activation of these MAPK pathways, with the best performance in $10 \mu \mathrm{M}$ allicin group. Then, the p38 inhibitor SB202190, the JNK inhibitor SP600125, and the ERK inhibitor SCH772984 were used to validate the activation of MAPK pathways. NP cells were pretreated, respectively, with allicin $(10 \mu \mathrm{M})$, SB202190 $(10 \mu \mathrm{M})$, SP600125 $(10 \mu \mathrm{M})$, and SCH772984 $(10 \mu \mathrm{M})$ for $2 \mathrm{~h}$, before being treated with AOPP for $24 \mathrm{~h}$. Compared with AOPPtreated group, in SB202190-treated group, we observed pro- moted proliferation, decreased level of ROS, downregulated cleaved caspase-3, and partial recovery of MTP, and these effects resembled the allicin-treated group (Figures 6(a)$6(d))$. The inhibited expression of p38 or p-p38 in SB202190-treated group was corroborated by Western blot (Figure S1(a), (b)). However, parts of such protective effects were not found in SP600125- or SCH772984-treated groups, where the cell viability, apoptosis rate, and relative ROS levels of NP cells resembled that of the AOPP alone treatment group (Figure S2). In summary, AOPP induced oxidative stress and activated mitochondrial apoptosis in NP cells via activation of p38-MAPK pathway, while allicin could exert protective effects against AOPP by inhibition of such signaling pathway.

3.7. p38-MAPK Agonist Could Block the Effects of Allicin on AOPP-Induced Oxidative Stress and Mitochondrial Apoptosis. To further examine whether inhibited p38MAPK pathway actually functioned in allicin-mediated protection against AOPP-induced oxidative stress and mitochondrial apoptosis, the p38-MAPK activator Dehydrocorydaline chloride (Dc) was used. The human NP cells were pretreated with allicin $(10 \mu \mathrm{M})$ or allicin $(10 \mu \mathrm{M})$ in combination with $\mathrm{Dc}(500 \mathrm{nM})$ for $2 \mathrm{~h}$, and then treated with AOPP $(400 \mu \mathrm{g} / \mathrm{ml})$ for $24 \mathrm{~h}$. The restrained cell proliferation, promoted apoptosis, ROS generation, and decrease of MTP induced by AOPP were mitigated to varying degrees in allicin pretreatment group, while these protective effects of allicin were markedly blocked by p38-MAPK agonist Dc 

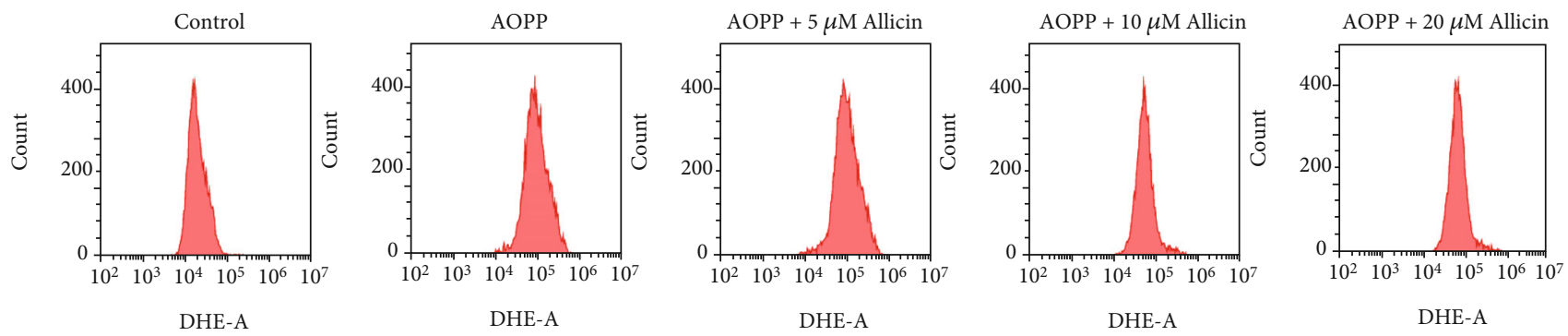

(a)

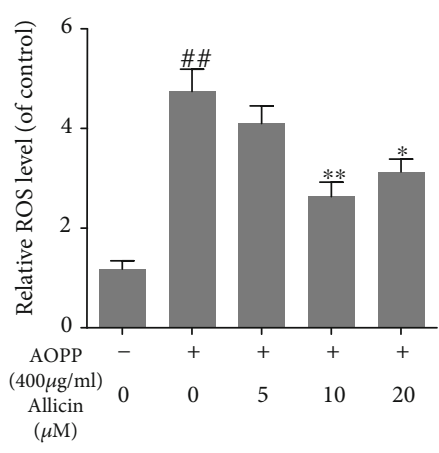

(b)

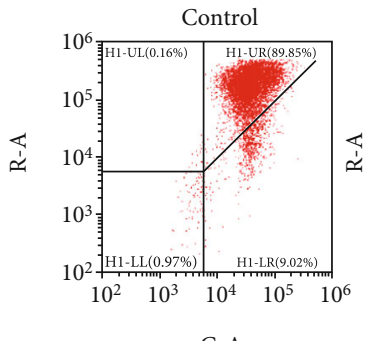

G-A

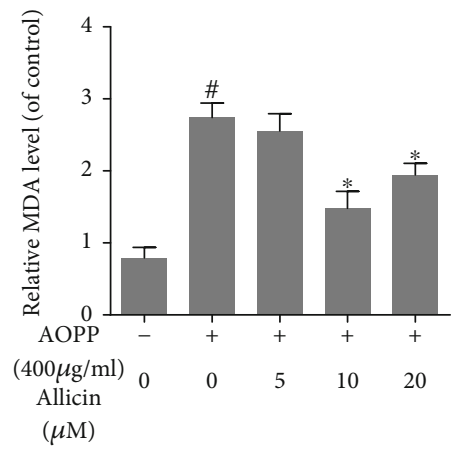

(c)

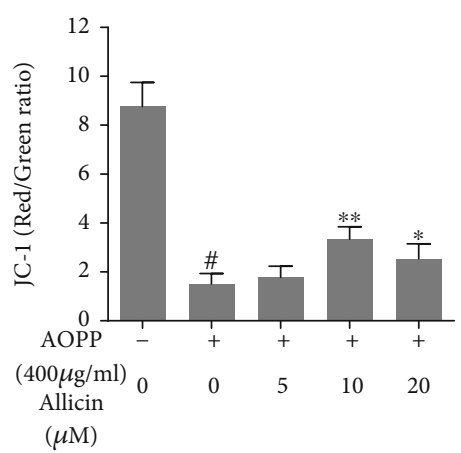

(d)
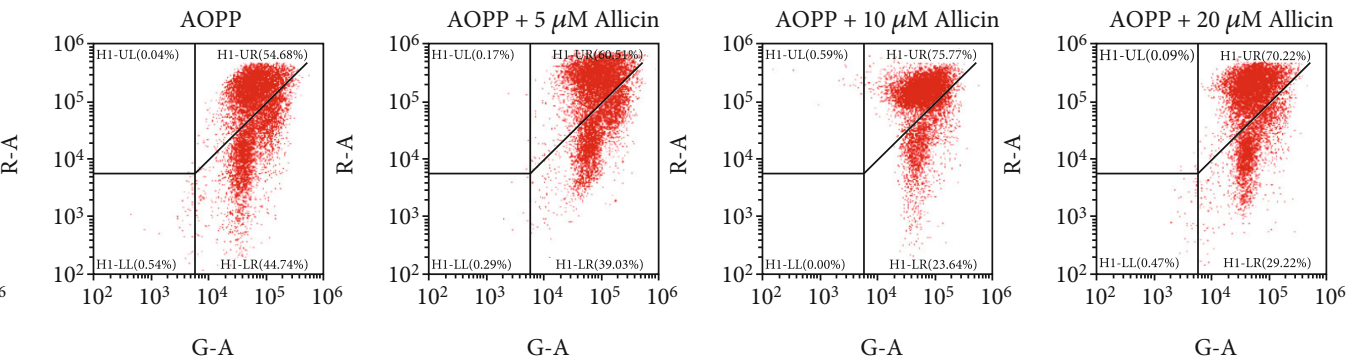

(e)

FIGURE 4: Allicin treatment inhibited AOPP-induced oxidative stress and mitochondrial dysfunction of human NP cells. (a, b) The human $\mathrm{NP}$ cells were pretreated with different concentrations of allicin $(0,5,10$, and $20 \mu \mathrm{M})$ for $2 \mathrm{~h}$, before treatment with $400 \mu \mathrm{g} / \mathrm{ml} \mathrm{AOPP}$ for $24 \mathrm{~h}$. The intracellular ROS levels of the NP cells for each group were detected by ROS-specific fluorescent probe DHE and measured by subsequent flow cytometry analysis. Representative peak charts of flow cytometry and relative quantitative analysis were shown. (c) The intracellular MDA levels (as a marker of lipid peroxidation) of human NP cells were examined by a commercial kit. (d, e) The mitochondrial membrane potential of human NP cells in each group was examined by JC-1 staining and measured by subsequent flow cytometry analysis. The quantitative analysis of the ratio of red fluorescence ( $y$ axis) to green fluorescence $(x$ axis) and representative scatter plots of flow cytometry were shown. Data were represented as mean \pm SD. ${ }^{\#} p<0.05$ and ${ }^{\# \#} p<0.01$ versus the control group; ${ }^{*} p<$ 0.05 and ${ }^{* *} p<0.01$ versus the AOPP alone treatment group, $n=3$.

(Figure 7). In short, inhibition of the p38-MAPK pathway was an important avenue mediating the effect of allicin on AOPP-induced oxidative stress and mitochondrial apoptosis.

\section{Discussion}

LBP is a cosmopolitan problem that has become not only a medical issue, but also a socioeconomic burden in contemporary society [39]. IDD is the main contributor to LBP [40]. Although many efforts have been made to alleviate the symptoms of IDD, valid pharmacotherapy to inhibit IDD progression is still missing, possibly due to an insufficient understanding of its etiology [17, 41]. As a joint outcome of various initiators, abnormal apoptosis of NP cells has been widely detected in degenerative discs and is considered one of the most common pathogenetic mechanisms of IDD [9]. In fact, the extent of apoptosis of cells in regressive disc specimens is $53 \% \sim 73 \%$, as reported previously [42].

Apoptotic pathways include the death receptor (also called the extrinsic) pathway and the mitochondrial (also called the intrinsic) pathway [43]. Cytochrome-c release, apoptotic body formation, and activating the caspase cascade are necessary components of the mitochondrial apoptotic pathway, which can be initiated by diverse factors including intracellular oxidative stress [44]. A newly described marker of oxidative stress in the serum is represented by AOPP, a group of protein products that contain dityrosine residues and are produced by oxidants, such as hypochlorous acid 


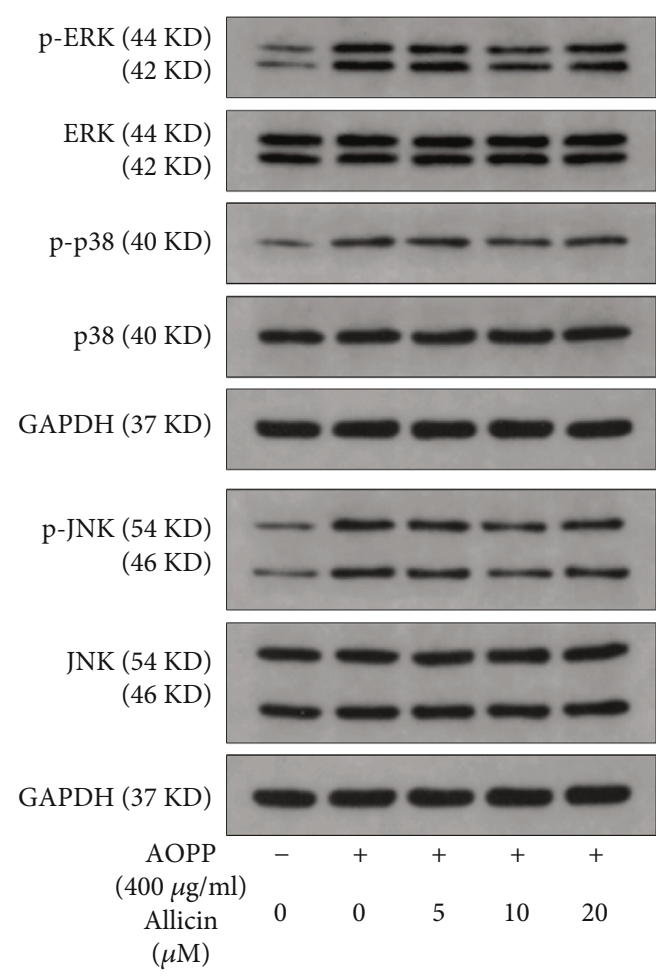

(a)

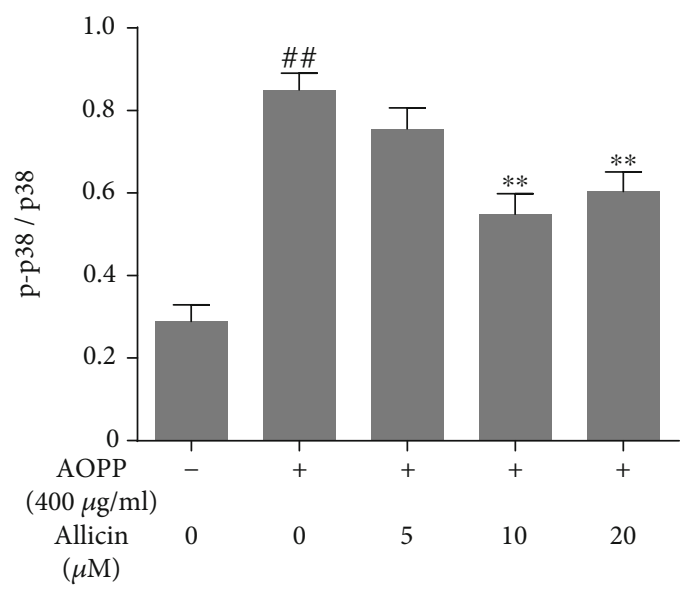

(c)

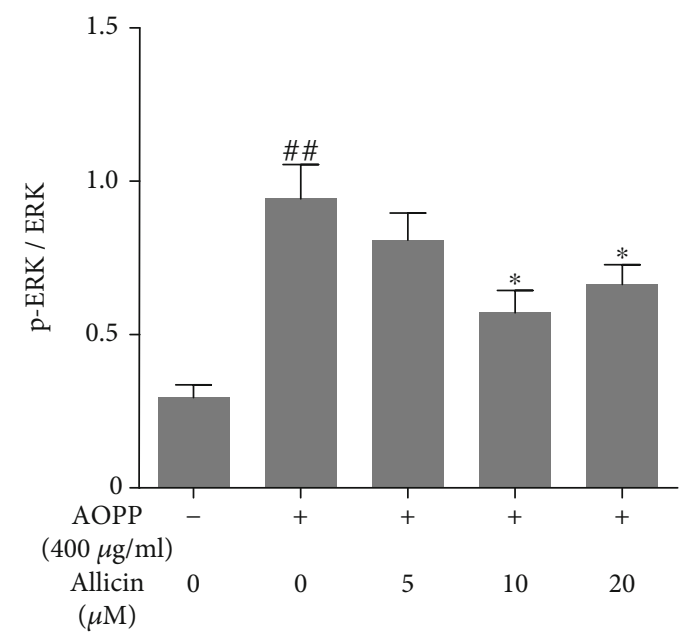

(b)

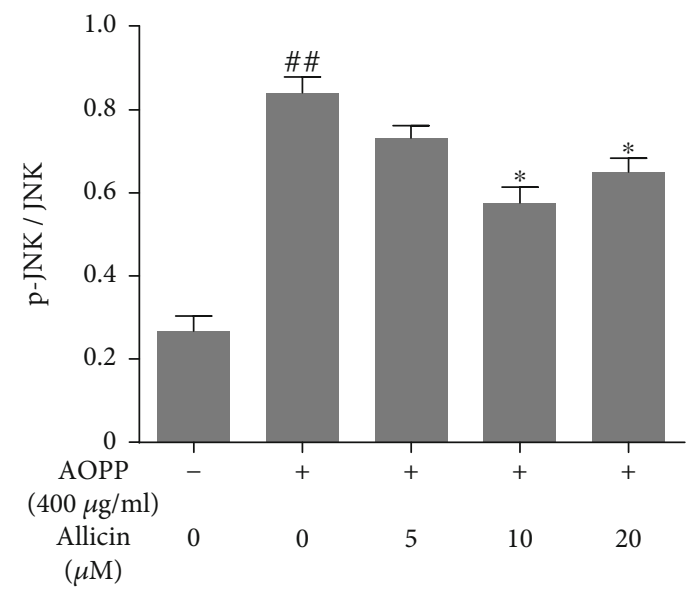

(d)

FIgURE 5: Effects of allicin on AOPP-induced MAPK pathway activation. (a) The human NP cells were pretreated with various concentrations of allicin $(0,5,10$, and $20 \mu \mathrm{M})$ for $2 \mathrm{~h}$, followed by stimulation with $400 \mu \mathrm{g} / \mathrm{ml}$ AOPP for $24 \mathrm{~h}$. The protein levels of ERK, phosphorylated ERK, p38, phosphorylated p38, JNK, and phosphorylated JNK were determined using Western blotting analysis. (b-d) Immunoblot bands corresponded to (b) p-ERK, (c) p-p38, and (d) p-JNK were quantified by densitometric analysis and normalized to their corresponding total kinase. Data were represented as mean \pm SD. ${ }^{\# \#} p<0.01$ versus the control group; ${ }^{*} p<0.05$ and ${ }^{* *} p<0.01$ versus the AOPP alone treatment group, $n=3$.

and chloramines secreted by activated neutrophils [45, 46]. However, recent studies have shown that AOPP are not only biomarkers of oxidative stress, but also a new type of oxidative pathogenic mediator [17]. To date, AOPP have been reported to be involved in several diseases, including progressive nephropathies and neuroinflammation, via a redoxdependent way [47, 48]. For example, a previous study showed that extracellular accumulation of AOPP triggered the production of ROS and induced apoptosis of dorsal root ganglion neurons [49]. However, it has not yet been elucidated whether the accumulation of AOPP can lead to apoptosis of human NP cells, which plays a key role in the pathogenesis of IDD. In the present study, we found disparities of the AOPP levels in between healthy (Pfirrmann I or II) and degenerated (Pfirrmann IV or V) human NP tissues. The levels of AOPP in the degenerated specimens were much higher than that in the healthy samples, which might suggest a pathogenic function of AOPP in IDD progression. 

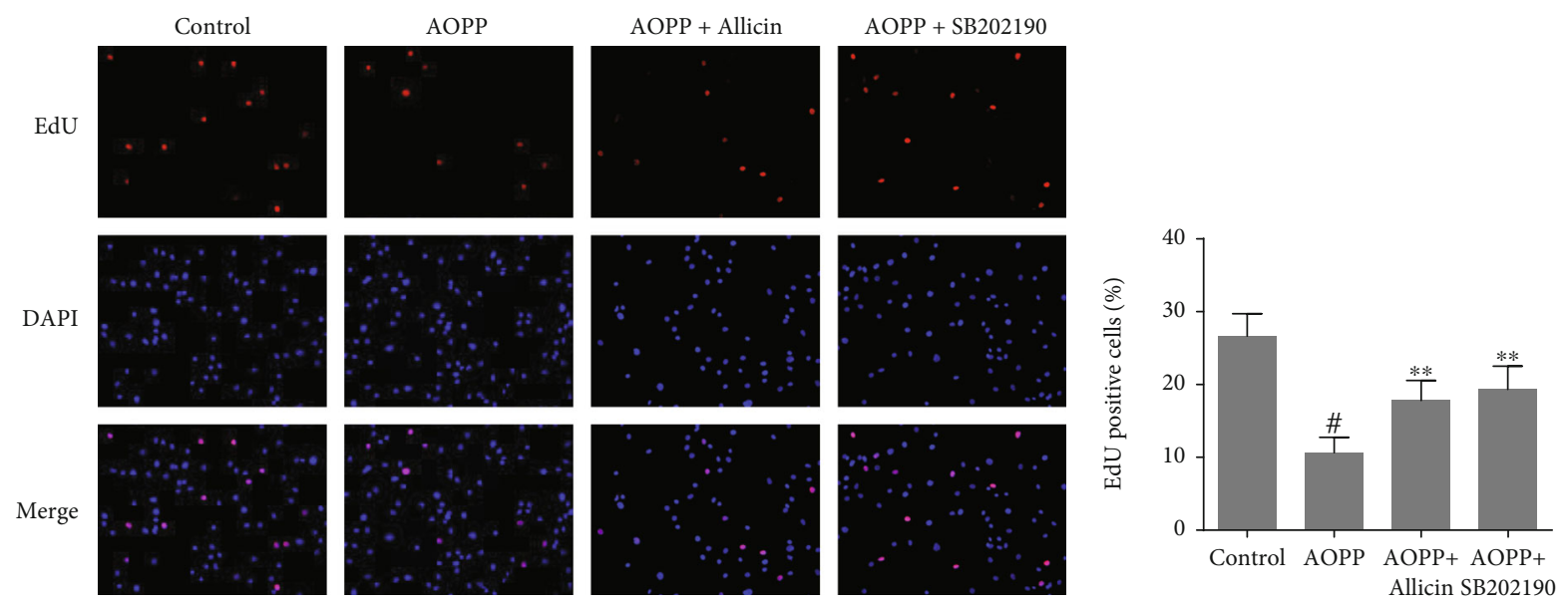

(a)
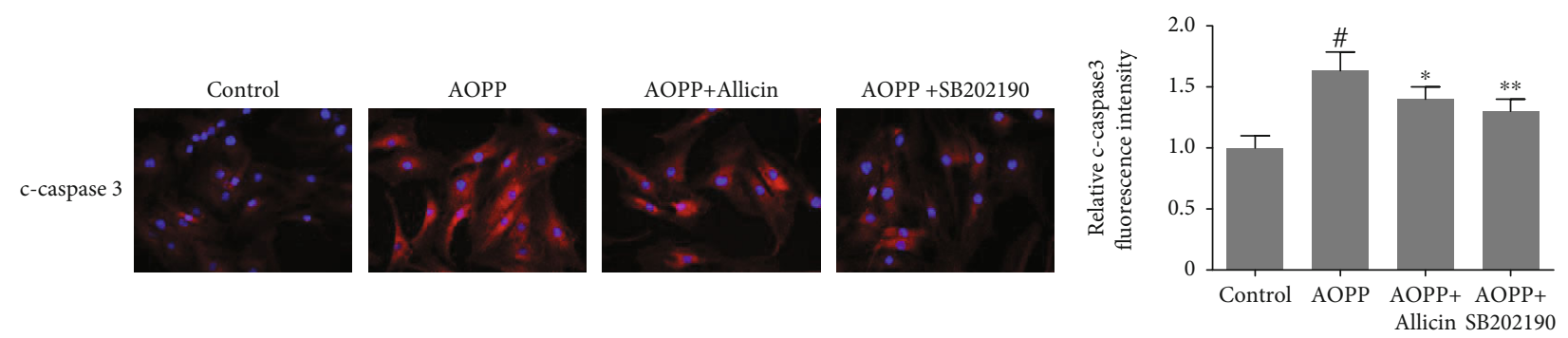

(b)
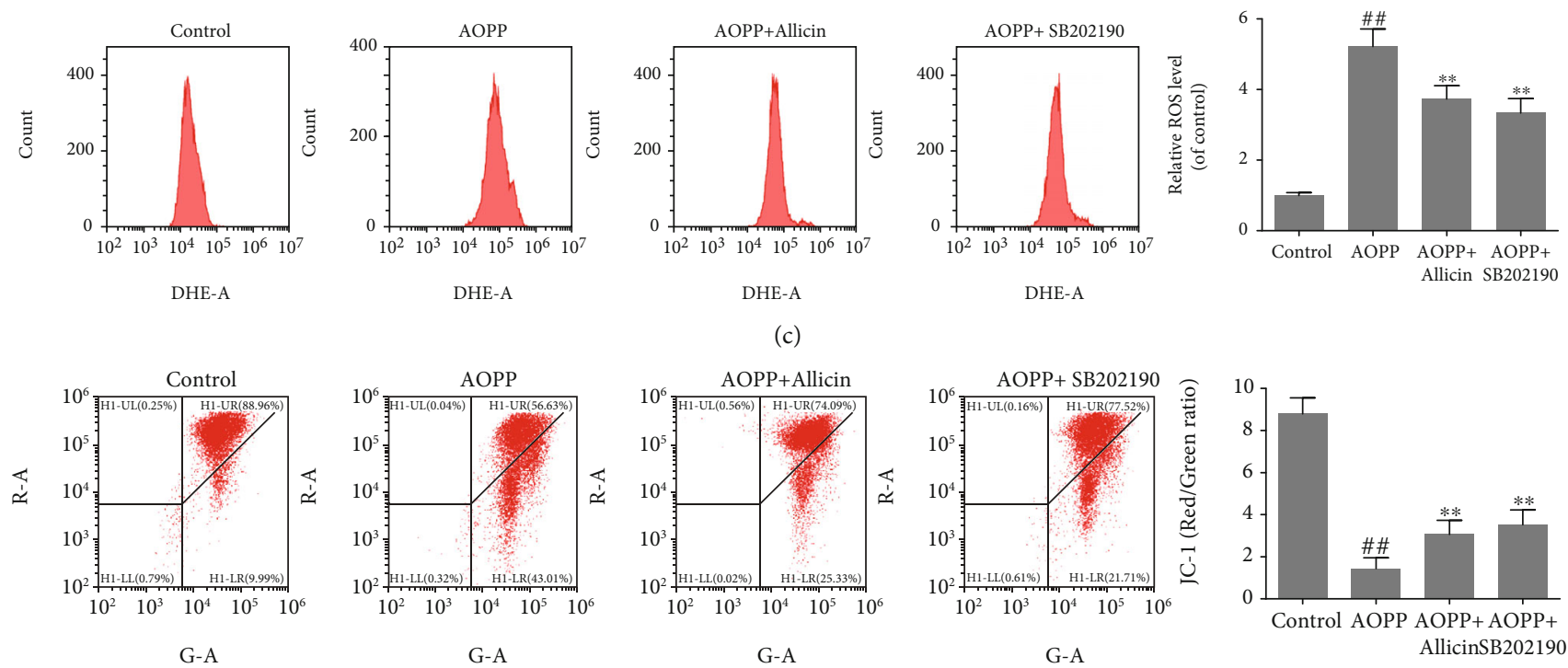

(c)
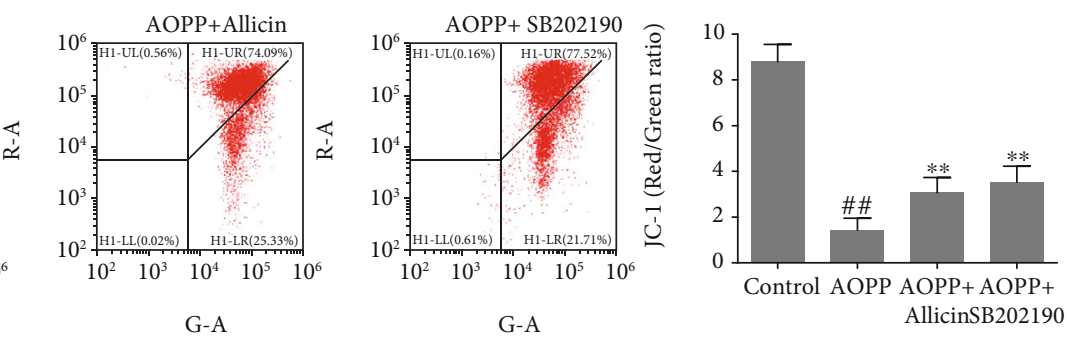

(d)

FIGURE 6: Allicin alleviated AOPP-induced oxidative stress and mitochondrial dysfunction via p38-MAPK pathway in human NP cells. (a) The human NP cells were pretreated with allicin $(10 \mu \mathrm{M})$ or p38-MAPK inhibitor SB202190 (10 $\mu \mathrm{M})$ for $2 \mathrm{~h}$, then treated with AOPP $(400 \mu \mathrm{g} / \mathrm{ml})$ for $24 \mathrm{~h}$. The cell proliferation was determined using EdU staining combined with DAPI staining for the nuclei under fluorescence microscope, with the EdU positive cells quantitated. Original magnification: $\times 200$. (b) Representative images of immunofluorescence staining for cleaved caspase- 3 in each group, with the relative fluorescence intensity quantified. Original magnification: $\times 400$. (c) The intracellular ROS levels of the NP cells for each group were detected by ROS-specific fluorescent probe DHE and measured by subsequent flow cytometry analysis. (d) The mitochondrial membrane potential of human NP cells in each group was examined by JC-1 staining and measured by subsequent flow cytometry analysis. Representative scatter plots of flow cytometry and the quantitative analysis of red fluorescence to green fluorescence ratio were shown. Data were represented as mean \pm SD. ${ }^{*} p<0.05$ and ${ }_{\# \#} p<0.01$ versus the control group; ${ }^{*} p<0.05$ and ${ }^{* *} p<0.01$ versus the AOPP alone treatment group, $n=3$. 

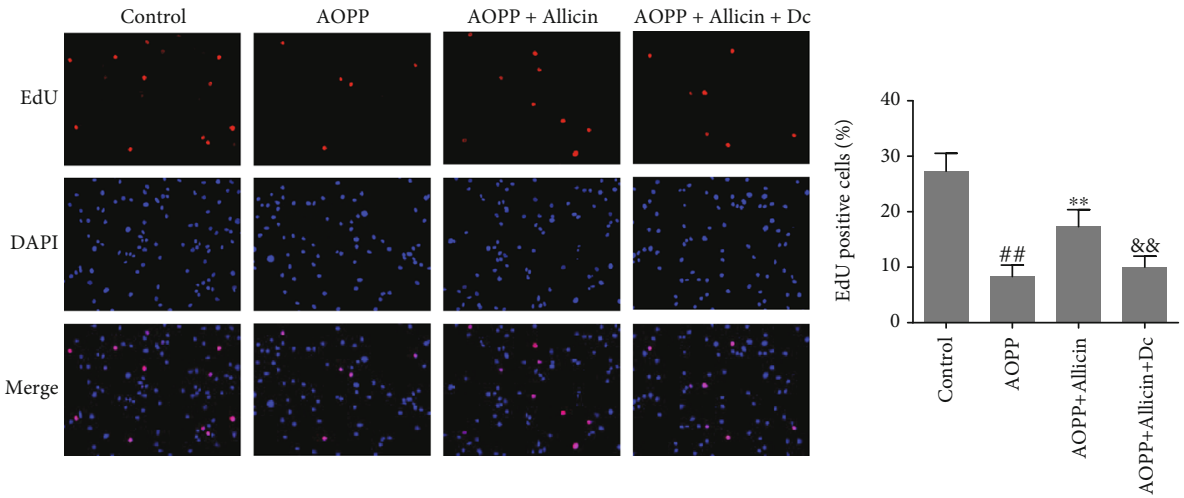

(a)
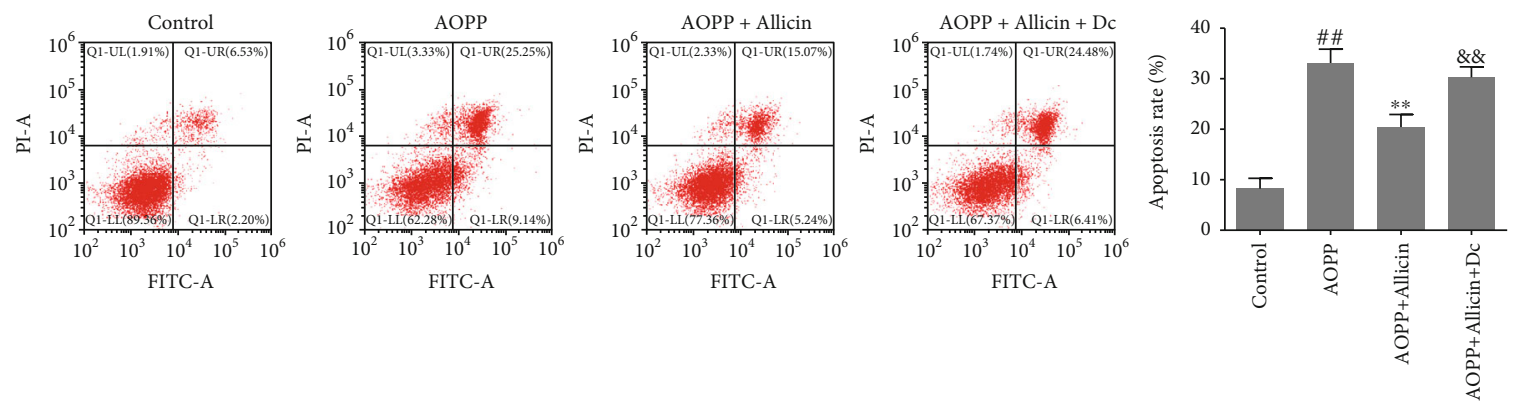

(b)
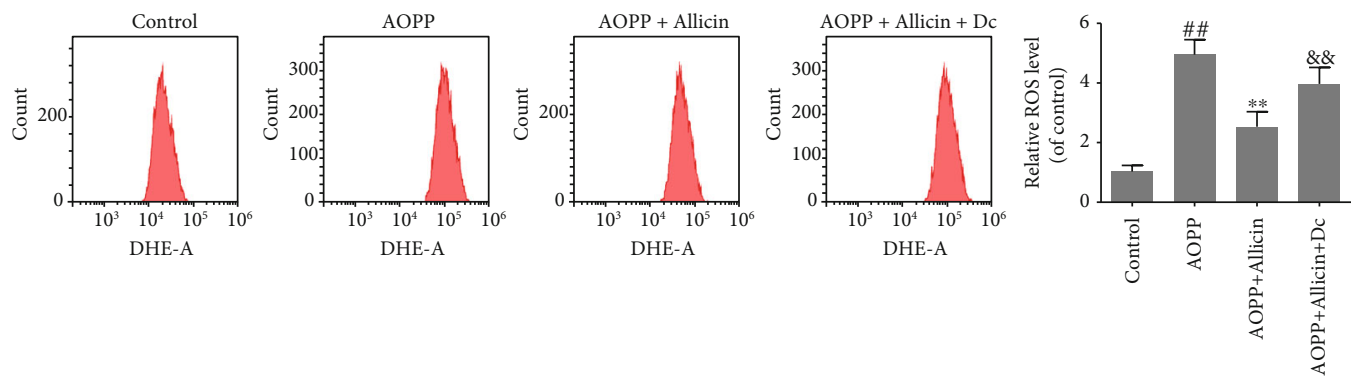

(c)
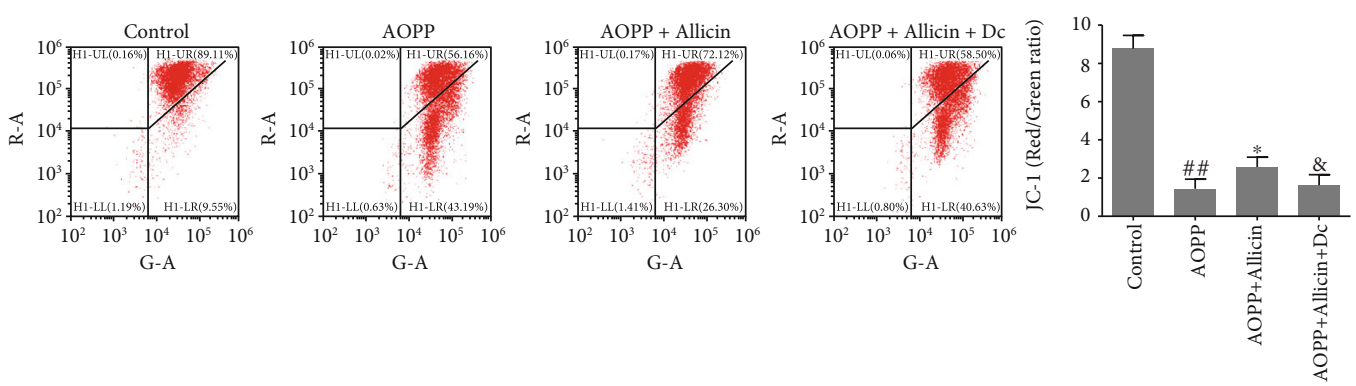

(d)

FIGURE 7: Allicin alleviated AOPP-induced oxidative stress and mitochondrial dysfunction via p38-MAPK pathway in human NP cells. (a) The human NP cells were pretreated with allicin $(10 \mu \mathrm{M})$ or allicin $(10 \mu \mathrm{M})$ in combination with p38-MAPK activator Dehydrocorydaline chloride $(\mathrm{Dc}, 500 \mathrm{nM})$ for $2 \mathrm{~h}$, then treated with AOPP $(400 \mu \mathrm{g} / \mathrm{ml})$ for $24 \mathrm{~h}$. The cell proliferation was determined by EdU staining combined with DAPI staining for the nuclei under fluorescence microscope, with the EdU positive cells quantitated. Original magnification: $\times 200$. (b) The cell apoptosis rate was detected by flow cytometry with Annexin V-FITC/PI dual staining. The proportion of apoptotic cells in the first and fourth quadrant was measured for analysis. (c) The intracellular ROS levels for each group were detected by ROS-specific fluorescent probe DHE and measured by subsequent flow cytometry analysis. (d) The mitochondrial membrane potential of human NP cells in each group was examined by JC-1 staining and measured by subsequent flow cytometry analysis. Data were represented as mean \pm SD. ${ }^{\# \#} p<0.01$ versus the control group, ${ }^{*} p<0.05$ and ${ }^{* *} p<0.01$ versus the AOPP alone treatment group, and ${ }^{\&} p<0.05$ and ${ }^{\& \&} p<0.01$ versus the AOPP+allicin treatment group, $n=3$. 
To explore the effects of AOPP on IDD, we separated NP cells from the healthy samples for further research. For the human NP cell isolation, since excessive time of digestion may be harmful to the cell viability, we chopped the NP tissue into small pieces to digest faster [50,51]. In addition, a noteworthy difficulty for us in primarily culturing human NP cells was contamination, and the combined use of penicillin and streptomycin effectively prevented microbial contamination in the cell culture. Next, we exposed well-grown human NP cells of second passage to different levels of AOPP and assessed cell viability, proliferation, and apoptosis using the CCK-8 assay, EDU staining, and flow cytometry, respectively. The results showed that AOPP restrained the activity and proliferation of NP cells in both concentration- and time-dependent manners and promoted cell apoptosis.

After treating NP cells with AOPP, we detected the overexpression of proapoptotic proteins, including Bax, cytochrome-c, cleaved caspase- 9 , and cleaved caspase-3, while the level of the antiapoptotic protein, $\mathrm{Bcl}-2$, was downregulated. This might be related to impaired mitochondrial function. Moreover, previous research found that AOPP could augment the level of ROS by activating NADPH oxidase, thus inducing preosteoblast apoptosis [19]. A leading source of cellular oxidative stress, ROS, is mainly derived from mitochondria, being generated in the electron transport chain $[52,53]$. Previous studies indicated that excess ROS increased the $\mathrm{Bax} / \mathrm{Bcl}-2$ ratio and damaged key intracellular targets, such as the mitochondrial membrane, thereby promoting apoptosis through the mitochondrial apoptotic pathway $[52,54,55]$. In the prophase of mitochondrial apoptosis, the mitochondrial membrane is oxidatively damaged after attack by ROS, resulting in enhanced mitochondrial outer membrane permeability and a decreased MTP [56-58]. Moreover, ROS overproduction also increases Bax/Bcl-2 ratio, which can further impair the mitochondrial membrane and decrease the MTP [55]. Depolarization of the MTP, as a characteristic change in the forepart of apoptosis, contributes to the release of apoptosis-inducing factor and cytochrome-c from mitochondria, which in turn triggers the activation of caspase- 9 and caspase- 3 , and the subsequent cascade of caspases, leading to the irreversible process of apoptosis [57, 59-62]. Therefore, our results indicated that AOPP might trigger the mitochondrial apoptosis pathway.

To further explore the mechanism underlying apoptosis, we first measured the intracellular levels of two main indicators of oxidative stress after treatment of NP cells with AOPP: ROS and malondialdehyde (MDA), a specific marker for lipid oxidation. As expected, the levels of both compounds were elevated, demonstrating the existence of AOPPinduced oxidative stress in NP cells. Then, we measured the MTP using the cationic fluorescent indicator, JC-1. The results showed depolarization of the MTP, suggesting mitochondrial dysfunction. A recent study targeting human chondrocytes revealed that AOPP could cause mitochondrial dysfunction in a ROS-dependent manner and induce apoptosis, in line with our findings [37].

As a natural compound extracted from garlic bulbs, allicin has been shown to exert potent antioxidant properties and is thus used as an antioxidant agent for the treatment of many diseases [63]. Previous studies have shown that allicin can reduce ROS levels, abate lipid peroxidation, and protect cells from apoptosis $[28,30,64,65]$. Considering the prominent antioxidant properties of allicin, we conjectured that it could antagonize AOPP-induced oxidative injury to NP cells and inhibit apoptosis. Therefore, we used AOPP as an oxidative source and explored the function of allicin. NP cells were pretreated with different levels of allicin before exposure to high concentrations of AOPP $(400 \mu \mathrm{g} / \mathrm{ml})$. Compared with the AOPP alone treatment group, allicinpretreated NP cells exhibited less apoptosis and a lower $\mathrm{Bax} / \mathrm{Bcl}-2$ ratio, as well as reduced expression of apoptosisrelated proteins including cleaved caspase- 3 and -9 and cytochrome-c, demonstrating that allicin could mitigate AOPPinduced apoptosis of NP cells.

We also measured the intracellular levels of ROS and MDA, which were decreased in allicin-pretreated groups compared with the AOPP alone treatment group. This supported the antioxidative capability of allicin. In addition, by measuring MTP, we showed that AOPP-induced mitochondrial damage in NP cells was attenuated in the allicinpretreated groups. Overall, our results showed that allicin could mitigate AOPP-induced oxidative stress and activation of the mitochondrial apoptosis pathway through its antioxidative properties in human NP cells, consistent with the results of Hong et al. [66] who discovered that allicin abated acrylamide-induced oxidative stress in BRL-3A cells. However, it is possible that these results do not represent the intracorporal effect of allicin, whose elucidation requires further experiments.

Mitogen-activated protein kinase (MAPK) signaling pathways are important avenues for apoptosis. MAPK is comprised of three chief subgroups: p38-MAPK, extracellular signal-regulated kinase (ERK), and c-Jun $\mathrm{N}$-terminal kinase (JNK) [67]. Previous studies have shown that the MAPK pathway is significantly involved in cell proliferation, differentiation, and apoptosis and can be activated by various inflammatory cytokines and cellular stressors, such as ultraviolet rays, DNA damage, and oxidative stress $[68,69]$. In particular, ROS engendered by NADPH oxidase are potent MAPK activators [70, 71]. Therefore, we choose to assess these primary members of the MAPK family to ascertain the signaling pathway underlying AOPP-induced apoptosis in NP cells and the protective role of allicin. The NP cells were treated with high levels of AOPP $(400 \mu \mathrm{g} / \mathrm{ml})$ before determining the levels of $\mathrm{p} 38$, ERK, JNK, and their phosphorylation forms. All three MAPK subfamilies were significantly activated by AOPP administration. According to previous studies, it is of note that p38-MAPK signaling pathway could also be activated in a time-dependent manner by various factors, such as LPS, TNF-alpha, and IL-1beta [72,73]. A similar assay was performed following treatment with different concentrations of allicin for $2 \mathrm{~h}$, and then with the highest level of AOPP $(400 \mu \mathrm{g} / \mathrm{ml})$ for $24 \mathrm{~h}$. Notably, we observed concentration-dependent inhibition of all the three MAPK pathways in the allicin-pretreated groups. Afterwards, p38 inhibitor SB202190, JNK inhibitor SP600125, and ERK inhibitor SCH772984 were used to validate the pathway involved in AOPP-induced apoptosis of NP cells and in the 
antagonistic effect of allicin against AOPP. It was of note that though all MAPK subfamilies were activated, the protective function against AOPP was found only when the p38, but not the JNK or ERK, was inhibited. The extent of apoptosis and the levels of ROS of the SB202190-treated group were significantly lower than that of the AOPP alone treatment group and were similar with that of allicin-treated group. Correspondingly, our results of Western blotting showed that the expression of p38 or p-p38 was decreased by allicin pretreatment. Next, we used the p38-MAPK activator Dc to further validate the role of inhibited p38-MAPK pathway in allicin-mediated protection against AOPP-induced oxidative stress and mitochondrial apoptosis. In the case of levels of apoptosis, MTP, ROS, and cell proliferation, the allicin and Dc combined pretreatment group was much closer to AOPP alone treatment group than the allicin alone pretreatment group, suggesting that the anti-AOPP effects of allicin were blocked by Dc. In summary, our experimental results revealed that allicin could mitigate AOPP-induced oxidative stress and mitochondrial apoptosis in NP cells by inhibiting activation of the p38-MAPK pathway.

In conclusion, our findings provide new insights into the etiology of apoptosis in NP cells and, more importantly, suggest that allicin may be a novel remedy to mitigate the progression of IDD. However, there are a few limitations to our study. Because all our observations were based on in vitro experiments, further research is required to validate these findings in vivo. In addition, because the use of allicin as a multifunctional medicine has a long history, its protective role in NP cells may also involve other mechanisms. Indeed, a prior study showed that allicin could mitigate the dexamethasone-induced abnormal expression of cytochrome-c, c-caspase 3, c-caspase 9, Bax, and Bcl-2 through activating the PI3K/AKT pathway, and thus rescued apoptosis of osteoblasts induced by dexamethasone in rats [74]. Another study revealed that allicin attenuated age-related cognitive dysfunction through activating Nrf2 antioxidant signaling pathways [75]. Therefore, further investigations focusing on molecular mechanisms are required to shed light on the antiapoptotic function of allicin against AOPP in NP cells.

Recently, the comparability between 3D culture in hypoxia and IVD microenvironment aroused our interest. The NP cells mainly obtain oxygen and nutrients through the osmosis of the cartilage endplate (CEP). During IDD, unexplained calcification of the CEP usually blocks this effect and helps to form hypoxic areas. Therefore, NP cells in IDD are likely to be hypoxic. In a $2 \mathrm{D}$ monolayer, all cells are exposed to the gas phase, but the internal area of the $3 \mathrm{D}$ culture is usually limited by diffusion, leading to hypoxia and necrosis [76]. Similarly, the distribution of NP cells is also $3 \mathrm{D}$ due to the thickness of IVD, which means that the internal cells are more prone to be anoxic than the cells close to the CEP. Therefore, 3D culture in hypoxia can better mimic the microenvironment in native IVDs. In addition, studies have shown that hypoxia can also influence intracellular oxidative stress. For example, exposure to hypoxia could restrict the generation of ROS in NP cells and inhibit apoptosis [77-79]. It can be inferred that hypoxia, a nonignorable variable in the human IVD, might have an impact on our research and change the existing experimental results of AOPP. Hence, applying 3D culture in hypoxia might better reflect the actual level of oxidative stress and apoptosis induced by AOPP in human NP cells. It is also helpful to better determine the pharmacodynamic curve of allicin for that the antioxidative function of allicin might be attenuated by hypoxia. Therefore, we are very interested in 3D culture under hypoxic conditions and hope to determine the effects of AOPP on NP cells in this context, which inspired our follow-up research. At the same time, more investigations in the future are needed to uncover the role of oxidative stress in IDD by using 3D culture in hypoxia.

\section{Abbreviations}

AOPP: Advanced oxidation protein products

LBP: Low back pain

IVD: Intervertebral disc

IDD: Intervertebral disc degeneration

NP: Nucleus pulposus

ECM: Extracellular matrix

AF: $\quad$ Annulus fibrosus

MAPK: Mitogen-activated protein kinase

ERK: Extracellular signal-regulated kinase

JNK: c-Jun N-terminal kinase

ROS: Reactive oxygen species

DHE: Dihydroethidium

MDA: Malondialdehyde

MTP: Mitochondrial transmembrane potential.

\section{Data Availability}

The data used to support the findings of this study were included within the article.

\section{Conflicts of Interest}

The authors reported no conflict of interest.

\section{Authors' Contributions}

Qian Xiang, Zhangrong Cheng, and Juntan Wang contributed equally to this work.

\section{Acknowledgments}

This study was supported by the grants from the National Natural Science Foundation of China (81772391, 81974348, and 81902260).

\section{Supplementary Materials}

Supplementary Figure S1: allicin alleviated AOPP-induced oxidative stress and mitochondrial dysfunction via p38MAPK pathway. Supplementary Figure S2: allicin alleviated AOPP-induced oxidative stress and mitochondrial dysfunction via p38-MAPK pathway. Supplementary Figure S3: the schematic diagram illustrating that allicin attenuated AOPP-induced oxidative stress and mitochondrial apoptosis in human NP cells. (Supplementary Materials) 


\section{References}

[1] T. Vos, A. A. Abajobir, K. H. Abate et al., "Global, regional, and national incidence, prevalence, and years lived with disability for 328 diseases and injuries for 195 countries, 19902016: a systematic analysis for the Global Burden of Disease Study 2016," The Lancet, vol. 390, no. 10100, pp. 1211-1259, 2017.

[2] R. Buchbinder, M. van Tulder, B. Öberg et al., "Low back pain: a call for action," Lancet, vol. 391, no. 10137, pp. 2384-2388, 2018.

[3] S. Yang, F. Zhang, J. Ma, and W. Ding, "Intervertebral disc ageing and degeneration: the antiapoptotic effect of oestrogen," Ageing Research Reviews, vol. 57, article 100978, 2020.

[4] D. Sakai and S. Grad, "Advancing the cellular and molecular therapy for intervertebral disc disease," Advanced Drug Delivery Reviews, vol. 84, pp. 159-171, 2015.

[5] C. Q. Zhao, L. M. Wang, L. S. Jiang, and L. Y. Dai, "The cell biology of intervertebral disc aging and degeneration," Ageing Research Reviews, vol. 6, no. 3, pp. 247-261, 2007.

[6] X. Wu, Z. Liao, K. Wang et al., "Targeting the IL-1 $\beta /$ IL-1Ra pathways for the aggregation of human islet amyloid polypeptide in an ex vivo organ culture system of the intervertebral disc," Experimental \& Molecular Medicine, vol. 51, no. 9, pp. 1-16, 2019.

[7] A. Slinskey, D. Barnes, and J. M. Pipas, "Simian virus 40 large $\mathrm{T}$ antigen $\mathrm{J}$ domain and Rb-binding motif are sufficient to block apoptosis induced by growth factor withdrawal in a neural stem cell line," Journal of Virology, vol. 73, no. 8, pp. 67916799, 1999.

[8] Z. Zhai, N. Ha, F. Papagiannouli et al., "Antagonistic regulation of apoptosis and differentiation by the cut transcription factor represents a tumor-suppressing mechanism in Drosophila," PLoS Genetics, vol. 8, no. 3, article e1002582, 2012.

[9] Z. Gao, Y. Lin, P. Zhang et al., "Sinomenine ameliorates intervertebral disc degeneration via inhibition of apoptosis and autophagy in vitro and in vivo," American Journal of Translational Research, vol. 11, no. 9, pp. 5956-5966, 2019.

[10] Y. H. Cheng, S. H. Yang, C. C. Liu, A. Gefen, and F. H. Lin, "Thermosensitive hydrogel made of ferulic acid-gelatin and chitosan glycerophosphate," Carbohydrate Polymers, vol. 92, no. 2, pp. 1512-1519, 2013.

[11] R. Luo, Z. Liao, Y. Song et al., "Berberine ameliorates oxidative stress-induced apoptosis by modulating ER stress and autophagy in human nucleus pulposus cells," Life Sciences, vol. 228, pp. 85-97, 2019.

[12] Z. Zhang, L. Rong, and Y. P. Li, "Flaviviridae viruses and oxidative stress: implications for viral pathogenesis," Oxidative Medicine and Cellular Longevity, vol. 2019, Article ID 1409582, 17 pages, 2019.

[13] E. Chierto, A. Simon, F. Castoldi et al., "Mechanical stretch of high magnitude provokes axonal injury, elongation of paranodal junctions, and signaling alterations in oligodendrocytes," Molecular Neurobiology, vol. 56, no. 6, pp. 4231-4248, 2019.

[14] M. L. Stama, E. Lacivita, L. N. Kirpotina et al., "Functional Nformyl peptide receptor 2 (FPR2) antagonists based on the ureidopropanamide scaffold have potential to protect against inflammation-associated oxidative stress," ChemMedChem, vol. 12, no. 22, pp. 1839-1847, 2017.

[15] V. Witko-Sarsat, M. Friedlander, C. Capeillère-Blandin et al., "Advanced oxidation protein products as a novel marker of oxidative stress in uremia," Kidney International, vol. 49, no. 5, pp. 1304-1313, 1996.

[16] F. Xie, S. Sun, A. Xu et al., "Advanced oxidation protein products induce intestine epithelial cell death through a redoxdependent, c-jun N-terminal kinase and poly (ADP-ribose) polymerase-1-mediated pathway," Cell Death \& Disease, vol. 5, no. 1, p. e1006, 2014.

[17] S. Sun, F. Xie, X. Xu et al., "Advanced oxidation protein products induce S-phase arrest of hepatocytes via the ROS-dependent, $\beta$-catenin-CDK2-mediated pathway," Redox Biology, vol. 14, pp. 338-353, 2018.

[18] R. Qi and C. Yang, "Renal tubular epithelial cells: the neglected mediator of tubulointerstitial fibrosis after injury," Cell Death \& Disease, vol. 9, no. 11, 2018.

[19] S. Y. Zhu, J. S. Zhuang, Q. Wu et al., “Advanced oxidation protein products induce pre-osteoblast apoptosis through a nicotinamide adenine dinucleotide phosphate oxidase-dependent, mitogen-activated protein kinases-mediated intrinsic apoptosis pathway," Aging Cell, vol. 17, no. 4, article e12764, 2018.

[20] L. L. Zhou, W. Cao, C. Xie et al., "The receptor of advanced glycation end products plays a central role in advanced oxidation protein products-induced podocyte apoptosis," Kidney International, vol. 82, no. 7, pp. 759-770, 2012.

[21] C. R. Liao, S. N. Wang, S. Y. Zhu et al., "Advanced oxidation protein products increase TNF- $\alpha$ and IL- $1 \beta$ expression in chondrocytes via NADPH oxidase 4 and accelerate cartilage degeneration in osteoarthritis progression," Redox Biology, vol. 28, article 101306, 2020.

[22] G. Hou, H. Lu, M. Chen, H. Yao, and H. Zhao, "Oxidative stress participates in age-related changes in rat lumbar intervertebral discs," Archives of Gerontology and Geriatrics, vol. 59, no. 3, pp. 665-669, 2014.

[23] A. Tekari, S. C. W. Chan, D. Sakai, S. Grad, and B. Gantenbein, "Angiopoietin-1 receptor Tie2 distinguishes multipotent differentiation capability in bovine coccygeal nucleus pulposus cells," Stem Cell Research \& Therapy, vol. 7, no. 1, 2016.

[24] M. A. Dkhil, D. Delic, H. A. El Enshasy, and A. E. Abdel Moneim, "Medicinal plants in therapy: antioxidant activities," Oxidative Medicine and Cellular Longevity, vol. 2016, Article ID 7468524, 2016.

[25] S. Hayat, Z. Cheng, H. Ahmad, M. Ali, X. Chen, and M. Wang, "Garlic, from remedy to stimulant: evaluation of antifungal potential reveals diversity in phytoalexin allicin content among garlic cultivars; allicin containing aqueous garlic extracts trigger antioxidants in cucumber," Frontiers in Plant Science, vol. 7, 2016.

[26] L. Wang, H. Jiao, J. Zhao, X. Wang, S. Sun, and H. Lin, “Allicin alleviates reticuloendotheliosis virus-induced immunosuppression via ERK/mitogen-activated protein kinase pathway in specific pathogen-free chickens," Frontiers in Immunology, vol. 8, 2017.

[27] R. T. M. Alam, E. M. Fawzi, M. I. Alkhalf, W. S. Alansari, L. Aleya, and M. M. Abdel-Daim, "Anti-inflammatory, Immunomodulatory, and antioxidant activities of allicin, norfloxacin, or their combination against Pasteurella multocida infection in male New Zealand rabbits," Oxidative Medicine and Cellular Longevity, vol. 2018, Article ID 1780956, 10 pages, 2018.

[28] M. Zhang, H. Pan, Y. Xu, X. Wang, Z. Qiu, and L. Jiang, “Allicin decreases lipopolysaccharide-induced oxidative stress and inflammation in human umbilical vein endothelial cells through suppression of mitochondrial dysfunction and 
activation of Nrf2," Cellular Physiology and Biochemistry, vol. 41, no. 6, pp. 2255-2267, 2017.

[29] C. Liu, F. Cao, Q. Z. Tang et al., "Allicin protects against cardiac hypertrophy and fibrosis via attenuating reactive oxygen species-dependent signaling pathways," The Journal of Nutritional Biochemistry, vol. 21, no. 12, pp. 1238-1250, 2010.

[30] M. M. Abdel-Daim, O. E. Kilany, H. A. Khalifa, and A. A. M. Ahmed, "Allicin ameliorates doxorubicin-induced cardiotoxicity in rats via suppression of oxidative stress, inflammation and apoptosis," Cancer Chemotherapy and Pharmacology, vol. 80, no. 4, pp. 745-753, 2017.

[31] M. L. Circu and T. Y. Aw, "Reactive oxygen species, cellular redox systems, and apoptosis," Free Radical Biology \& Medicine, vol. 48, no. 6, pp. 749-762, 2010.

[32] L. Shi, H. Qin, X. Jin et al., “The natural phenolic peperobtusin A induces apoptosis of lymphoma U937 cells via the Caspase dependent and p38 MAPK signaling pathways," Biomedicine \& Pharmacotherapy, vol. 102, pp. 772-781, 2018.

[33] Y. Song, S. Li, W. Geng et al., "Sirtuin 3-dependent mitochondrial redox homeostasis protects against AGEs-induced intervertebral disc degeneration," Redox Biology, vol. 19, pp. 339353, 2018.

[34] M. Hanasand, R. Omdal, K. B. Norheim, L. G. Gøransson, C. Brede, and G. Jonsson, "Improved detection of advanced oxidation protein products in plasma," Clinica Chimica Acta, vol. 413, no. 9-10, pp. 901-906, 2012.

[35] X. Zhang, Y. Kang, T. Huo et al., "GL-V9 induced upregulation and mitochondrial localization of NAG-1 associates with ROS generation and cell death in hepatocellular carcinoma cells," Free Radical Biology \& Medicine, vol. 112, pp. 49-59, 2017.

[36] J. Wang, M. Nisar, C. Huang et al., "Small molecule natural compound agonist of SIRT3 as a therapeutic target for the treatment of intervertebral disc degeneration," Experimental \& Molecular Medicine, vol. 50, no. 11, pp. 1-14, 2018.

[37] W. Ye, S. Zhu, C. Liao et al., "Advanced oxidation protein products induce apoptosis of human chondrocyte through reactive oxygen species-mediated mitochondrial dysfunction and endoplasmic reticulum stress pathways," Fundamental \& Clinical Pharmacology, vol. 31, no. 1, pp. 64-74, 2017.

[38] K. Wang, B. Chen, T. Yin et al., "N-Methylparoxetine Blocked autophagic flux and induced apoptosis by activating ROS-MAPK pathway in non-small cell lung Cancer Cells," International Journal of Molecular Sciences, vol. 20, no. 14, p. 3415, 2019.

[39] D. Lin, P. Alberton, M. Delgado Caceres et al., "Loss of tenomodulin expression is a risk factor for age-related intervertebral disc degeneration," Aging Cell, vol. 19, no. 3, p. e13091, 2020.

[40] J. N. Katz, "Lumbar disc disorders and low-back pain: socioeconomic factors and consequences," The Journal of Bone and Joint Surgery. American, vol. 88, Supplement 2, p. 21, 2006.

[41] P. H. Wu, H. S. Kim, and I. T. Jang, "Intervertebral disc diseases PART 2: a review of the current diagnostic and treatment strategies for intervertebral disc disease," International Journal of Molecular Sciences, vol. 21, no. 6, p. 2135, 2020.

[42] J. W. Chen, B. B. Ni, B. Li, Y. H. Yang, S. D. Jiang, and L. S. Jiang, "The responses of autophagy and apoptosis to oxidative stress in nucleus pulposus cells: implications for disc degeneration," Cellular Physiology and Biochemistry, vol. 34, no. 4, pp. 1175-1189, 2014.

[43] S. Nagata, "Apoptosis by death factor," Cell, vol. 88, no. 3, pp. 355-365, 1997.
[44] S. Deegan, S. Saveljeva, S. E. Logue et al., "Deficiency in the mitochondrial apoptotic pathway reveals the toxic potential of autophagy under ER stress conditions," Autophagy, vol. 10, no. 11, pp. 1921-1936, 2014.

[45] C. Capeillère-Blandin, V. Gausson, B. Descamps-Latscha, and V. Witko-Sarsat, "Biochemical and spectrophotometric significance of advanced oxidized protein products," Biochimica et Biophysica Acta, vol. 1689, no. 2, pp. 91-102, 2004.

[46] I. Sadowska-Bartosz, S. Galiniak, G. Bartosz, and M. Rachel, "Oxidative modification of proteins in pediatric cystic fibrosis with bacterial infections," Oxidative Medicine and Cellular Longevity, vol. 2014, Article ID 389629, 10 pages, 2014.

[47] W. Cao, F. F. Hou, and J. Nie, "AOPPs and the progression of kidney disease," Kidney International. Supplement, vol. 4, no. 1, pp. 102-106, 2014.

[48] Z. Liu, X. Yao, W. Jiang et al., "Advanced oxidation protein products induce microglia-mediated neuroinflammation via MAPKs-NF- $\kappa$ B signaling pathway and pyroptosis after secondary spinal cord injury," Journal of Neuroinflammation, vol. 17, no. 1, 2020.

[49] R. Ding, B. Sun, Z. Liu et al., “Advanced oxidative protein products cause pain hypersensitivity in rats by inducing dorsal root ganglion neurons apoptosis via NADPH oxidase 4/c-Jun N-terminal kinase pathways," Frontiers in Molecular Neuroscience, vol. 10, 2017

[50] X. Feng, L. Liu, B. Q. Yu, J. M. Huang, L. D. Gu, and D. F. Xu, "Effect of optimized collagenase digestion on isolated and cultured nucleus pulposus cells in degenerated intervertebral discs," Medicine, vol. 97, no. 44, article e12977, 2018.

[51] Q. Xiang, L. Kang, J. Wang et al., "CircRNA-CIDN mitigated compression loading-induced damage in human nucleus pulposus cells via miR-34a-5p/SIRT1 axis," eBioMedicine, vol. 53, article 102679, 2020.

[52] M. Schieber and N. S. Chandel, "ROS function in redox signaling and oxidative stress," Current Biology, vol. 24, no. 10, pp. R453-R462, 2014.

[53] D. B. Zorov, M. Juhaszova, and S. J. Sollott, "Mitochondrial reactive oxygen species (ROS) and ROS-induced ROS release," Physiological Reviews, vol. 94, no. 3, pp. 909-950, 2014.

[54] D. Trachootham, J. Alexandre, and P. Huang, "Targeting cancer cells by ROS-mediated mechanisms: a radical therapeutic approach?," Nature Reviews. Drug Discovery, vol. 8, no. 7, pp. 579-591, 2009.

[55] B. Zhang, X. Zhang, C. Zhang, Q. Shen, G. Sun, and X. Sun, "Notoginsenoside $\mathrm{R} 1$ protects $\mathrm{db} / \mathrm{db}$ mice against diabetic nephropathy via upregulation of Nrf2-mediated HO-1 expression," Molecules, vol. 24, no. 2, p. 247, 2019.

[56] K. J. Kinghorn, J. I. Castillo-Quan, F. Bartolome et al., "Loss of PLA2G6 leads to elevated mitochondrial lipid peroxidation and mitochondrial dysfunction," Brain, vol. 138, no. 7, pp. 1801-1816, 2015.

[57] J. D. Ly, D. R. Grubb, and A. Lawen, "The mitochondrial membrane potential (deltapsi(m)) in apoptosis; an update," Apoptosis, vol. 8, no. 2, pp. 115-128, 2003.

[58] Y. Tan, Y. Jin, Q. Wang, J. Huang, X. Wu, and Z. Ren, “Perilipin 5 protects against cellular oxidative stress by enhancing mitochondrial function in HepG2 cells," Cells, vol. 8, no. 10, p. 1241, 2019.

[59] N. Zamzami, P. Marchetti, M. Castedo et al., "Sequential reduction of mitochondrial transmembrane potential and 
generation of reactive oxygen species in early programmed cell death," The Journal of Experimental Medicine, vol. 182, no. 2, pp. 367-377, 1995.

[60] M. C. Maiuri, E. Zalckvar, A. Kimchi, and G. Kroemer, "Selfeating and self-killing: crosstalk between autophagy and apoptosis," Nature Reviews. Molecular Cell Biology, vol. 8, no. 9, pp. 741-752, 2007.

[61] D. R. Green and G. Kroemer, "The pathophysiology of mitochondrial cell death," Science, vol. 305, no. 5684, pp. 626629, 2004.

[62] W. Hu and J. J. Kavanagh, "Anticancer therapy targeting the apoptotic pathway," The Lancet Oncology, vol. 4, no. 12, pp. 721-729, 2003.

[63] J. Borlinghaus, F. Albrecht, M. C. Gruhlke, I. D. Nwachukwu, and A. J. Slusarenko, "Allicin: chemistry and biological properties," Molecules, vol. 19, no. 8, pp. 12591-12618, 2014.

[64] S. Chen, Y. Tang, Y. Qian et al., “Allicin prevents H2O2induced apoptosis of HUVECs by inhibiting an oxidative stress pathway," BMC Complementary and Alternative Medicine, vol. 14, no. 1, 2014.

[65] J. Y. Chan, A. C. Yuen, R. Y. Chan, and S. W. Chan, “A review of the cardiovascular benefits and antioxidant properties of allicin," Phytotherapy Research, vol. 27, no. 5, pp. 637-646, 2013.

[66] Y. Hong, B. Nan, X. Wu, H. Yan, and Y. Yuan, "Allicin alleviates acrylamide-induced oxidative stress in BRL-3A cells," Life Sciences, vol. 231, article 116550, 2019.

[67] J. Yue and J. M. López, "Understanding MAPK signaling pathways in apoptosis," International Journal of Molecular Sciences, vol. 21, no. 7, p. 2346, 2020.

[68] Q. Liu, B. Tao, G. Liu et al., “Thromboxane A2 receptor inhibition suppresses multiple myeloma cell proliferation by inducing p38/c-Jun N-terminal kinase (JNK) mitogenactivated protein kinase (MAPK)-mediated G2/M progression delay and cell apoptosis," The Journal of Biological Chemistry, vol. 291, no. 9, pp. 4779-4792, 2016.

[69] J. D. Ashwell, "The many paths to p38 mitogen-activated protein kinase activation in the immune system," Nature Reviews. Immunology, vol. 6, no. 7, pp. 532-540, 2006.

[70] Y. Son, Y. K. Cheong, N. H. Kim, H. T. Chung, D. G. Kang, and H. O. Pae, "Mitogen-activated protein kinases and reactive oxygen species: how can ROS activate MAPK pathways?" Journal of Signal Transduction, vol. 2011, Article ID 792639, 6 pages, 2011.

[71] K. W. Zeng, F. J. Song, Y. H. Wang et al., "Induction of hepatoma carcinoma cell apoptosis through activation of the JNKnicotinamide adenine dinucleotide phosphate (NADPH) oxidase-ROS self-driven death signal circuit," Cancer Letters, vol. 353, no. 2, pp. 220-231, 2014.

[72] L. Li, J. Hu, T. He et al., "P38/MAPK contributes to endothelial barrier dysfunction via MAP4 phosphorylation-dependent microtubule disassembly in inflammation-induced acute lung injury," Scientific Reports, vol. 5, no. 1, 2015.

[73] N. Tang, Y. P. Zhang, W. Ying, and X. X. Yao, "Interleukin-1 $\beta$ upregulates matrix metalloproteinase-13 gene expression via c-Jun N-terminal kinase and p38 MAPK pathways in rat hepatic stellate cells," Molecular Medicine Reports, vol. 8, no. 6, pp. 1861-1865, 2013.

[74] J. Zhan, Z. Yan, M. Zhao et al., "Allicin inhibits osteoblast apoptosis and steroid-induced necrosis of femoral head progres- sion by activating the PI3K/AKT pathway," Food \& Function, vol. 11, no. 9, pp. 7830-7841, 2020.

[75] X. H. Li, C. Y. Li, J. M. Lu, R. B. Tian, and J. Wei, “Allicin ameliorates cognitive deficits ageing-induced learning and memory deficits through enhancing of Nrf2 antioxidant signaling pathways," Neuroscience Letters, vol. 514, no. 1, pp. 46-50, 2012.

[76] K. M. McMahon, M. Volpato, H. Y. Chi et al., "Characterization of changes in the proteome in different regions of 3D multicell tumor spheroids," Journal of Proteome Research, vol. 11, no. 5, pp. 2863-2875, 2012.

[77] J. W. Chen, B. B. Ni, X. F. Zheng, B. Li, S. D. Jiang, and L. S. Jiang, "Hypoxia facilitates the survival of nucleus pulposus cells in serum deprivation by down-regulating excessive autophagy through restricting ROS generation," The International Journal of Biochemistry \& Cell Biology, vol. 59, pp. 110, 2015.

[78] L. B. Jiang, L. Cao, Y. Q. Ma et al., “TIGAR mediates the inhibitory role of hypoxia on ROS production and apoptosis in rat nucleus pulposus cells," Osteoarthritis and Cartilage, vol. 26, no. 1, pp. 138-148, 2018.

[79] H. J. Kim, H. R. Lee, H. Kim, and S. H. Do, "Hypoxia helps maintain nucleus pulposus homeostasis by balancing autophagy and apoptosis," Oxidative Medicine and Cellular Longevity, vol. 2020, Article ID 5915481, 13 pages, 2020. 